\title{
The Decline of the U.S. Labor Share Across Sectors
}

\section{Ivan Mendieta-Muñoz*, Codrina Rada ${ }^{\dagger}$ and Rudi von Arnim*}

\section{Working Paper No. 105}

\author{
October 2019
}

\begin{abstract}
This paper provides novel insights on the changing functional distribution of income in the postwar US economy. We present a Divisia index decomposition of the US labor share (1948-2017) by fourteen sectors. The decomposition method furnishes exact contributions from four components towards aggregate changes of the labor share: sectoral real compensation, sectoral labor productivity, the structure of the economy as measured by employment shares, and the structure of markets as measured by relative prices. Results are presented for the entire period as well as the "golden age" (1948-1979) and a "neoliberal era" (1979-2017), painting a rich and detailed picture of structural changes in the US economy. The manufacturing sector plays a dominant role: despite its continuously falling employment share, growth of real compensation matches that of labor productivity in the early period but falls far behind during the neoliberal

\footnotetext{
* Assistant Professor, Department of Economics, University of Utah

Corresponding author: rada@economics.utah.edu; Associate Professor, Department of Economics, University of Utah. The authors gratefully acknowledge financial support from the Institute for New Economic Thinking (INET), and helpful comments from Thomas Ferguson, Robert Pollin, Lance Taylor and participants at the conference on "The Great Polarization" in Salt Lake City, UT, Sept. 2018, and the Amit Bhaduri Festschrift Conference held at University of Massachusetts Amherst on March 22-23, 2019. We further thank two anonymous reviewers for their comments. The usual disclaimer applies.

₹ Associate Professor, Department of Economics, University of Utah
} 
era. Further, employment shifts towards stagnant sectors with relatively low real wages and productivity. We discuss these results in the context of Baumol's and Lewis's seminal contributions on dual economies. While the cost disease is apparent-employment shifts towards stagnant sectors, their relative prices rise, and the aggregate growth rate (of productivity) decreases - the originally suggested mechanism of upward real wage convergence is muted. The observed changes are instead compatible with a "reverse-Lewis" shift, where stagnant sectors act as a labor surplus sink, and dynamic sector labor experiences slowing real wage growth.

https://doi.org/10.36687/inetwp105

JEL Codes: D33, C43, O41, O5

Keywords: Labor share, sectoral decomposition, stagnation, Baumol, Lewis 


\section{Introduction}

This paper presents novel findings on the sources of the decline in the Unites States (US) labor share in recent decades. We provide a systematic analysis of sectoral contributions to changes in the aggregate labor share using a Divisia index decomposition of US data from 1948 to 2017. Specifically, we present statistics on contributions to the aggregate labor share from changes in sectoral real wage, sectoral labor productivity, the structure of the economy as measured by employment shares, and the structure of markets as measured by terms-of-trade or relative prices.

Our paper situates itself within the fast growing literature on the changing nature of the distribution of income and the associated rise in income inequality. Several studies have used decomposition methods to delineate drivers of change of the aggregate labor share, and have employed regression analysis to identify its correlates (Elsby et al., 2013; Autor et al., 2017; IMF, 2017; Böckerman and Maliranta, 2012). These studies have emphasized simple shift-share effects, or focused on analysis at the firm level.

Our contribution to this literature lies in the focus on sectoral dynamics: we provide detailed documentation of the evolution of sectoral pay, productivity, output and employment over time, and specifically how these trajectories feed into the changing labor share using a Divisia index-based decomposition that has certain desirable properties as outlined in Section 3. We then delineate the stark differences of aggregate and sectoral labor share changes during the immediate post-war period, often dubbed a "golden age" of capitalism (1948-1979), and the subsequent decades, often dubbed the "neoliberal era" (1979-2017) — for a substantive discussion, see Marglin and Schor (1992).

Finally, our contribution is also related to the recent literature on structural change observed in developed countries motivated mainly by the numerous concerns and issues raised by deindustrialization. van Neuss (2019) presents a comprehensive survey of some of this literature that focuses on four drivers of structural change: changes in aggregate real income, changes in relative (sectoral) prices, changes in input-output (sectoral) linkages, and changes in comparative advantages via trade. In our paper, we discuss our findings in the context of the seminal contributions on multi-sector growth and development of Baumol's cost disease and Lewis's dual economy model of development. Baumol is the first to provide insights on the relationship between cross-sector differences in technology, changes in relative prices and changes in the structure of advanced economies; while Lewis offers a simple analytical framework for the relationship between structural change, growth and income distribution. Our choice of the theoretical context is motivated by the desire to highlight the basic intuition of our findings. ${ }^{1}$

\footnotetext{
${ }^{1}$ It must be duly noted, however, that Baumol and Lewis' contributions have each been generalized into a comprehensive literature that seeks answers to questions that intersect with the ones
} 
Key results can be summarized as follows. First, growth of real compensation and labor productivity dominate the overall change in the labor share both in the short term and over longer time horizons. Second, the manufacturing sector plays a critical role throughout the entire post-war period. Initially, strong real compensation gains relative to labor productivity growth increase the labor share. In the later period, the accelerating collapse of employment in manufacturing coincides with strong growth of labor productivity, which in turn consistently exceeds that of real compensation. Third, sectors with rising employment shares feature on average lower real compensation and lower labor productivity growth, and furthermore higher labor shares. These structural changes thus imply downward pressure on labor productivity growth, and at the same time buffer the overall decline of the labor share.

Based on these results we hypothesize that the U.S. economy is increasingly becoming a dual economy, where high productivity sectors - such as manufacturing - and high pay sectors - such as finance and professional services - co-exist with low pay and low productivity sectors that employ most workers. This hypothesis has been put forth by others; for important contributions see Storm (2017) and Temin (2017). However, their analyses focus on labor productivity growth (or total factor productivity growth) and wage inequality, rather than the functional distribution of income. Similar to Storm (2017), we seek to connect observed changes in the (functional) distribution of income and the structure of the economy to the hypothesis of secular stagnation.

The centrally important insight here is that the forces at play are certainly not (only) of Baumolian type. The mechanism suggested in Baumol (1967) assumes homogenous labor in a competitive labor market and upward real wage convergence: in the dynamic sector, nominal wages grow with labor productivity growth, whereas nominal wages and prices rise in the stagnant sector. As a result, growth rates of sectoral real consumption wages equilibrate, and match that of aggregate labor productivity, leaving the labor share unchanged. Our empirical findings confirm the phenomena of the cost disease, but not this mechanism. Instead, dynamic sectors show slowing real wage growth, as surplus labor is absorbed in stagnant sectors with lower real wages. Hence, profit shares in dynamic activities rise due to weak real wage growth, whereas stagnant sector profit shares are supported only by price increases. This pattern, as suggested in Taylor and Ömer (2018), is consistent with a "reverse-Lewis" shift, where the existence of surplus labor in stagnant sectors puts a significant drag on real wage growth in dynamic sectors. These results hold despite a potential bias in the data: the decline in the labor share is greatly limited by the tremendous surge in income flows categorized as salaries of CEOs, including, among others, certain stock options and bonuses.

we raise in this paper. Several recent surveys (Kruger, 2008; Herrendorf et al., 2014) highlight old and new theories of structural change, however these contributions largely leave out considerations of income distribution, which is the main topic of our paper. 
The remainder of the paper is organized as follows. The following section discusses various definitions of the labor share, and offers details on the particular measure constructed here based on sector-specific data. Section 3 presents the Divisia decomposition technique as applied to the components of the labor share across sectors, and the following Section 4 discusses results for the post-war period and the subsamples of golden age and neoliberal era. Section 5 analyzes these findings in the context of Baumol's and Lewis's ideas on two-sector models. Finally, we briefly conclude.

\section{Measuring the labor share}

What is labor's share of income? Measurement of the labor share is not straightforward, and several problems typically arise. First, it is not clear what properly can be counted as compensation for work. Is the contracted salary of superstar CEOs really labor income, or are such flows rather rents and hence profit-like income? Further, it is not clear what portion of income from self-employment should be treated as renumeration for work. And, it is not obvious which economic activities should or should not be included in an accounting of the total.

In this section, we seek to disentangle some of these issues. The main purpose is to circumscribe and motivate our approach to constructing a measure of the labor share based on a consistent set of sectoral accounts of production and distribution. Inevitably, to do so forces us to make assumptions. To foreshadow these, our measure of the labor share (i) focuses on private economic activity, (ii) is based on gross income flows, (iii) excludes real estate and the associated imputed rental income, (iv) applies the corporate payroll share to non-corporate income streams, and (v) excludes taxes on production and imports.

To begin, let us lay out some terminology. In much of this, we follow Elsby et al. (2013), who provide a useful discussion of these issues. First, the payroll share is the share of employee compensation in total income - it thus excludes income from self-employment, alternatively labeled as non-corporate income. It includes wages, salaries and supplements, which are in turn composed of employer contributions for employee pension and insurance funds, and for government social insurance. Second, and as mentioned, payrolls need to be augmented by non-employee labor income. The BLS publishes the labor share for the nonfarm business sector that includes an estimate of such non-corporate labor income. This so-called headline measure serves as a standard reference, so we begin with it here.

[Figure 1: Aggregate labor share]

Panel (a) of Figure 1 reports the BLS headline measure and two potential alternatives, namely the corporate payroll share, and the payroll share in gross domestic income. These three series differ both in numerator and denominator. For one, only 
the third includes compensation of employees in the public sector. Only the first addresses the problem of allocating some portion of self-employment income. All three are based on gross measures of income. A key issue here is that all three series portray different medium term trends. Specifically, only the third series shows an increase in the labor share during the golden age, and the subsequent decline during the neoliberal era. BLS headline measure and the corporate compensation share show, roughly, stability during the golden age, and a decline after 1980 (BLS) or 2000 (corporate).

Panel (b) delves further into the corporate data. Several issues stand out. The corporate profit share - net operating surplus relative to gross corporate value addedsaw a sustained decrease followed by recovery, with the turning point only in the mid-Nineties. Further, taxes on production and imports as a share of gross value added is roughly stable throughout the post-war period. On the basis of this relative constancy of the tax share, we exclude this flow from our data set. ${ }^{2}$

In sharp contrast, both supplements and depreciation show important medium term trends. The expansion of the social safety net drove a steep increase in the share of corporate contributions towards employee benefits, from about three percent in 1948 to twelve percent in the first quarter of 1993. These increases largely substituted for wages and salaries, as the relative stability of the payroll share indicates. After 1993, the share of employer contributions (to both private and public insurance plans) declined as a share of income. In summary, and clearly, any measure of the labor share must include supplements. The depreciation share of corporate gross value added takes flight in the early Seventies. What drives the increase? Certainly, the changing nature of technology plays a role here, since both computers and software depreciate faster than buildings and machinery. However, since the standards for accounting for depreciation are conventional and, crucially, depreciation presents an income flow at a point in time, it should as well be incorporated.

Next, we consider which activities should or should not be included in the total. Let us begin with public payrolls. First, government's net capital share in nonmarket activities is zero by construction. ${ }^{3}$ However, the evolution of public payrolls appears to matter for economy-wide developments. The expansion of public sector employment after the second world war seems to have strengthened the labor share. ${ }^{4}$ If public employment affects bargaining in other sectors, it would be preferable to include it in any study on the sources of the decline of the total labor share. However,

\footnotetext{
${ }^{2}$ On this and other issues, we conducted robustness tests. The exclusion of taxes on production and imports does not have a significant impact on results. Details are available upon request.

${ }^{3}$ See the BEA's NIPA Handbook, especially chapter 9; available at https://www.bea.gov/resources/methodologies/nipa-handbook, accessed May 17, 2019.

${ }^{4}$ Recall the black line in Panel (a) of Figure 1. This is based on NIPA Table 1.10, which does not report public compensation separately. According to NIPA Table 1.12, the share of public compensation in national income - assuming fixed supplement shares, which likely biases it downwards - increased from eight percent in 1948 to 14 percent in 1970.
} 
while measurement of payrolls in the public sector is straightforward, an assessment of labor productivity - necessary for the decompositions - is complicated both due to the imputation of output at cost, and the treatment of capital. Our dataset therefore includes only private activity.

The real estate sector represents a different quandary. Rognlie (2015) discusses it in detail. The concern is that only about one-fifth of income in the real estate sector are wages, and that a large majority of that capital share do not represent a monetary flow, but an imputed rent. These rents are assigned as capital income to homeowners, but are not available for expenditures, are likely artificially inflated due to trends in rents, and possibly reflect labor by homeowners themselves. As Rognlie (2015, p.13) puts it, "housing [...] does not conform to the traditional story of labor versus capital, nor can its growth be easily explained with many of the stories commonly proposed for the income split elsewhere in the economy, such as the bargaining power of labor and the role of technology." In summary, we exclude the entire real estate sector from our data set.

A different issue arises with regard to the very high incomes of top earners, particularly in finance but in other sectors as well. As already alluded to, it is not clear whether CEO pay (or that of other "superstars", see Gordon and Dew-Becker, 2008) truly represents labor income, or rather rents. Data accumulated by Piketty and collaborators indicate that the share of national income accruing to the bottom fifty percent of the income distribution has fallen dramatically since 1980; see Panel B of Figure 1 in Alvaredo et al. (2018). Needless to emphasize, income of the bottom fifty percent truly are wages paid for work. Similarly, Figure 4 in Elsby et al. (2013) which is based on the same data - documents that the bottom ninety percent share of corporate labor compensation showed stability during the golden age, but decreased by about ten percentage points between the mid-Seventies and the onset of the Great Recession. EPI's well-known wage-and-productivity tracker (see Bivens et al., 2014) provides further detail: until 1973, cumulative growth of the average real wage of production and non-supervisory workers, making up about four-fifth of employees in the Current Employment Statistics, matched that of economy-wide growth of labor productivity. In the mid-Seventies, a gap opened that only became wider in subsequent decades. The evidence clearly indicates that average real labor income has fallen dramatically relative to labor productivity. A different issue arises with regard to the very high incomes of top earners, particularly in finance but in other sectors as well. As already alluded to, it is not clear whether CEO pay (or that of other "superstars", see Gordon and Dew-Becker, 2008) truly represents labor income, or rather rents. Data accumulated by Piketty and collaborators indicate that the share of national income accruing to the bottom fifty percent of the income distribution has fallen dramatically since 1980; see Panel B of Figure 1 in Alvaredo et al. (2018). Needless to emphasize, income of the bottom fifty percent truly are wages paid for work. Similarly, Figure 4 in Elsby et al. (2013) — which is based 
on the same data - documents that the bottom ninety percent share of corporate labor compensation showed stability during the golden age, but decreased by about ten percentage points between the mid-Seventies and the onset of the Great Recession. EPI's well-known wage-and-productivity tracker (see Bivens et al., 2014) provides further detail: until 1973, cumulative growth of the average real wage of production and non-supervisory workers, making up about four-fifth of employees in the Current Employment Statistics, matched that of economy-wide growth of labor productivity. In the mid-Seventies, a gap opened that only became wider in subsequent decades. The evidence clearly indicates that average real labor income has fallen dramatically relative to labor productivity.

Further, top incomes in the distribution of wages and salaries are confounded by the use of stock options. A significant portion of executive pay in the corporate sector is structured as non-qualified stock options. These are included in this measure of labor compensation, but in this context of a discussion of the functional distribution of income might be more appropriately classified as capital income. Of course, and as previously argued, even base salaries of CEOs could be seen as a form of rent, or a form of distribution of profit. Clearly, trends in the payroll share are muted due to the tremendous increase in wage inequality, and the runaway gains of the top $1 \%$ of the compensation distribution. In summary, we would argue that wage and salary income at the very top of the distribution should be excluded from an ideal measure of the labor share. Since this can not be done in a consistent fashion for the sectoral data set used here, we proceed without such adjustments. ${ }^{5}$ However, the potential bias introduced is to limit the decline in the labor share. This implies that the measure presented and analyzed here should be seen as a conservative estimate of the decline of compensation relative to productivity.

Last but not least: what portion of self-employment income should be allocated to the labor share? Only the payroll share can unambiguously be attributed to labor. Underlying the BLS headline measure is the assumption that hourly wages in the corporate sector and self-employment are the same. This amounts to adjusting the payroll share by the ratio of self-employment hours to corporate hours. The assumption is ad-hoc, and appears to be violated: the distribution of non-corporate income flows differs from that of payrolls, and has changed over time in different ways. At the sectoral level and in our data set, it is also difficult to replicate. We therefore assume instead that non-corporate activity features the same labor share as corporate activity. This amounts to adjusting the payroll share by the ratio of non-corporate income to total income. We hence implicitly assume (i) that the "real

\footnotetext{
${ }^{5}$ For a related discussion, see Barrales and von Arnim (2017, p. 201), who adjust the aggregate corporate payroll share by the share of wages of the top one percent. The resulting proxy of the "bottom ninety nine percent" of payrolls, in their paper relative to corporate net value added, shows a steady trend increase from 1948-1980, and a steady decrease thereafter. Related insightful discussion focused on the role of managers and their incomes, including the role of stock options can be found in Duménil and Lévy (2015) and Lazonick (2015).
} 
wages" of the self-employed reflect their labor productivity, and (ii) that the ratio of the two is equal to that in corporate activities. ${ }^{6}$ While we find this underlying rationale defensible, it is as well ad-hoc. However, it can easily be implemented, and hence we proceed in this fashion.

Finally, the bottom four panels of Figure 1 summarize the aggregate labor share resulting from the aggregation of our sectoral data set. ${ }^{7}$ Panel (c) reports the three main components as a share of total value added: clearly, aggregate non-corporate income declines as a share of total value added from above twenty percent to about ten. Panel (d) shows different possible allocations of non-corporate income flows to the labor share, following the discussion in Elsby et al. (2013, section I.B). The top line in Panel (d) allots all non-corporate income to labor; the middle line excludes non-corporate income from the denominator; and the black line applies the payroll share to non-corporate income flows. The first corresponds to the "all-to-labor" measure, the second to the "economy-wide" measure. The third is our preferred approach. The bottom two panels compare that to the BLS-provided headline nonfarm business sector labor share.

The resulting labor share in the aggregate shows a sustained increase during the golden age, and a substantial decline during the neoliberal era. It peaks in 1970, and experiences annual compound growth of almost one half percentage point (19481970). Until 1979, annual compound growth amounts to three-tenths of a percentage point, in line with the labor share leveling off in the Seventies. The medium term trends of the measure constructed here thus conform more closely to the share of total payrolls in gross domestic income than the BLS headline number or corporate payrolls. ${ }^{8}$ It does so, however, for different reasons - our measure does not include public payrolls, but excludes real estate.

\footnotetext{
${ }^{6}$ In other words, the ratio of real income to productivity is the same in corporate and noncorporate activities: suppose, for the sake of the argument, that both types of workers produce the same output, but the self-employed require more hours. Our assumption implies that their real hourly income will be lower as well, to obtain the same labor share as in corporate activities.

${ }^{7}$ The data set covers fourteen sectors: (1) AGR: Agriculture, forestry and fishing; (2) MIN: Mining; (3) UTI Utilities; (4) CON: Construction; (5) MAN: Manufacturing; (6) WTR: Wholesale trade; (7) RTR: Retail trade; (8) TRW: Transportation and warehousing; (9) INF: Information; (10) FIN: Finance and insurance; (11) PBS: Professional and business services; (12) EHS: Education, health and social services; (13) AER: Arts, entertainment and recreation; (14) OTH Other services. A comprehensive discussion of these sectors and the necessary SIC-NAICS crosswalk and related matters is available upon request.

${ }^{8}$ See Figure 1 Panel (a). The annual compound growth rate of total payrolls in GDI from 19481970 (which represents the series' peak) is as well close to one half percentage point. Again, one might compare this to the labor share in Barrales and von Arnim (2017, Figure 2).
} 


\section{A Divisia decomposition of the labor share}

We take the aggregate labor share to be a Divisia index that captures changes in sectoral quantities of output and employment, as well as sectoral prices of goods and services and labor compensation. Index decomposition analysis dates back to the 1970s when it was used to assess the effect of changes in the structure of industrial production on energy demand. Decomposition techniques have since been refined and applied widely across disciplines including economics. Development and growth economics in particular have been concerned with the interaction of changing economic structure and economic growth ever since the mercantilists, and more formally since Leontief's seminal contribution on input-output analysis (Dietzenbacher and Los, 1998). Critically, the Divisia index decomposition has the desirable theoretical property of being a symmetric and additive indicator of relative change (Ang, 2004). Its discrete representation as a Törnqvist index is also a good approximation of the Fisher ideal index that lies behind data provided by the Bureau of Economic Analysis, our source of data for the exercise in this paper (Dumagan, 2002).

Building on Diewert (2010), we detail in the following paragraphs the decomposition technique for the labor share, which is generally defined as the ratio of nominal values

of the wage bill and value added. If there are $i$ sectors the labor share can be written as:

$$
\psi=\frac{\sum_{i=1}^{n} w_{i} L_{i}}{\sum_{i=1}^{n} P_{i} X_{i}}
$$

where $w_{i}, L_{i}, P_{i}, X_{i}$ are the nominal wage, employment, price level and quantity of output at the sectoral level. Multiplying equation (1) by $P L / P L$ we get

$$
\psi=\frac{\sum_{i=1}^{n} w_{i} L_{i}}{P L} \frac{P L}{\sum_{i=1}^{n} P_{i} X_{i}}=\omega / \varepsilon
$$

where $\omega, \varepsilon$ are the average real wage and productivity. These can in turn be disaggregated:

$$
\begin{aligned}
& \omega=\frac{\sum_{i=1}^{n} w_{i} L_{i}}{P L}=\sum_{i=1}^{n} \omega_{i} \lambda_{i} \\
& \varepsilon=\frac{\sum_{i=1}^{n} P_{i} X_{i}}{P L}=\sum_{i=1}^{n} \frac{P_{i} X_{i}}{P L_{i}} \frac{L_{i}}{L}=\sum_{i=1}^{n} p_{i} \varepsilon_{i} \lambda_{i}
\end{aligned}
$$


where $\omega_{i}, \varepsilon_{i}, \lambda_{i}, p_{i}$ indicate real compensation or the nominal wage deflated by the general price level $P$, labor productivity, employment share and terms-of-trade at the sectoral level. Using equations (3) and (4) the aggregate labor share can be written as

$$
\psi=\frac{\sum_{i=1}^{n} \omega_{i} \lambda_{i}}{\sum_{i=1}^{n} p_{i} \varepsilon_{i} \lambda_{i}}
$$

The overall labor share can now be decomposed into several contributing factors. Changes in the sectoral real wage and labor productivity amount to shift effects; changes in the structure of the economy as measured by the employment shares are perceived as structural or share effects while changes in the terms-of trade are market structure effects.

Assuming that all variables are continuous, differentiating equation (5) with respect to time, $t$, and dividing both sides by $\psi$ yields:

$$
\begin{aligned}
d \ln (\psi) / d t=\sum \phi_{i}\left[d \ln \left(\omega_{i}\right) / d t+d\right. & \left.\ln \left(\lambda_{i}\right) / d t\right] \\
& -\sum \theta_{i}\left[d \ln \left(p_{i}\right) / d t+d \ln \left(\varepsilon_{i}\right) / d t+d \ln \left(\lambda_{i}\right) / d t\right]
\end{aligned}
$$

The weights $\phi_{i}$ and $\theta_{i}$ are the nominal share of sector's $i$ wage compensation in total wage compensation and the sector's $i$ share in total value added. ${ }^{9}$ Integrating equation (6) over the interval $[t-n, t]$ gives the Divisia decompositions of the growth rate of the economy-wide labor share:

$$
\begin{aligned}
\ln \frac{\psi_{t}}{\psi_{t-n}}= & \int_{t-n}^{t} \sum \phi_{i}\left[d \ln \left(\omega_{i}\right) / d t\right]+\int_{t-n}^{t} \sum \phi_{i}\left[d \ln \left(\lambda_{i}\right) / d t\right] \\
& -\int_{t-n}^{t} \sum \theta_{i}\left[d \ln \left(p_{i}\right) / d t\right]-\int_{t-n}^{t} \sum \theta_{i}\left[d \ln \left(\varepsilon_{i}\right) / d t\right] \\
& -\int_{t-n}^{t} \sum \theta_{i}\left[d \ln \left(\lambda_{i}\right) / d t\right]
\end{aligned}
$$

Applying the exponential to equation (7) we get:

$$
D_{T}=D_{\omega} D_{\lambda} D_{p}^{-1} D_{\varepsilon}^{-1}
$$

where the terms represent contributions from real compensation $\omega$, employment structure $\lambda$, relative prices $p$ and labor productivity $\varepsilon$ to the total change $D_{T}$, re-

\footnotetext{
${ }^{9}$ For the wage bill the nominal and real labor shares are the same since both the numerator and the denominator are deflated with the same price index.
} 
spectively:

$$
\begin{aligned}
& D_{\omega}=\exp \left[\int_{t-n}^{t} \sum \phi_{i}\left[d \ln \left(\omega_{i}\right) / d t\right]\right. \\
& D_{\lambda}=\exp \left[\int_{t-n}^{t} \sum\left(\phi_{i}-\theta_{i}\right)\left[d \ln \left(\lambda_{i}\right) / d t\right]\right. \\
& D_{p}=\exp \left[\int_{t-n}^{t} \sum \theta_{i}\left[d \ln \left(p_{i}\right) / d t\right]\right. \\
& D_{\varepsilon}=\exp \left[\int_{t-n}^{t} \sum \theta_{i}\left[d \ln \left(\varepsilon_{i}\right) / d t\right]\right.
\end{aligned}
$$

To match the discrete format of the data we can write the components of the decomposition in discrete terms:

$$
\begin{aligned}
D_{\omega} & =\exp \left[\sum\left(\phi_{i, t}+\phi_{i, t-n}\right) / 2 \ln \left(\omega_{i, t} / \omega_{i, t-n}\right)\right] \\
D_{\lambda} & =\exp \left[\sum\left[\left(\phi_{i, t}+\phi_{i, t-n}\right) / 2-\left(\theta_{i, t}+\theta_{i, t-n}\right) / 2\right] \ln \left(\lambda_{i, t} / \lambda_{i, t-n}\right)\right] \\
D_{p} & =\exp \left[\sum\left(\theta_{i, t}+\theta_{i, t-n}\right) / 2 \ln \left(p_{i, t} / p_{i, t-n}\right)\right] \\
D_{\varepsilon} & =\exp \left[\sum\left(\theta_{i, t}+\theta_{i, t-n}\right) / 2 \ln \left(\varepsilon_{i, t} / \varepsilon_{i, t-n}\right)\right]
\end{aligned}
$$

The sectoral components of real wage and labor productivity have the same effect on the aggregate labor share as the aggregate real wage and aggregate labor productivity in equation (2). A positive change in the real wage in sector $i$ raises the labor share, while a positive change in the sector's labor productivity lowers the labor share. The real wage component is weighted by the sector's share in the wage bill, while labor productivity has the sector's share in value added as the weight.

The interpretation of the structural component - equation (14) - is more nuanced. If a sector's share of employment declines, $\ln \left(\lambda_{i}\right)$ is negative. However, if the sector's labor share is below the aggregate labor share, the weight is negative since $\phi_{i}-\theta_{i}=$ $\psi_{i} / \psi-1$. It follows that the aggregate labor share increases when employment shares decline for sectors with lower than average labor shares. This apparent improvement in the labor share is not necessarily a good thing if the sector that sheds labor (in either relative or absolute terms) is a sector with higher than average real wage and labor productivity. In this case the change in the structure of the economy takes place towards sectors with higher labor share yet a lower productivity and therefore a lower real wage in absolute terms. We will return to these issues further below in the discussion of results.

The last component of the decomposition is the change in the terms-of-trade captured by equation (15). A positive value means that the sector's price level grew faster than the general price level and, as a result, the sector contributed negatively 
to the aggregate labor share. Intuitively, sectors with rapidly rising price levels contribute more in relative terms to a rise in the general price level and therefore to a lower real wage. As an example, there would be no effect of individual sectoral terms-of-trade on the wage if price levels in all sectors grew at the same rate. This would also imply that the general price level $P$ grows at the uniform sectoral rate. At the aggregate level, changes in the sectoral terms-of-trade reflect changes in the structure of the economy. As shown by Diewert (2010), the contribution from the relative price component exceeds unity, and thus reduces the aggregate labor share, if sectors with relatively high labor productivity also have fast growing prices relative to the rest of the economy.

The following section provides detailed results of this method, applied to the sectoral labor share measure discussed previously.

\section{Results: The drivers of labor share changes in the US}

In this section, we present the main results of the Divisia index decomposition of the labor share. The focus will be on the distinction between the golden age and the neoliberal era, and structural changes occurring throughout. The topic of the next section is a contextualization of these results vis-à-vis Baumol and Lewis, but we will foreshadow some of the issues here.

\section{[Figure 2: Component contributions to aggregate labor share change]}

To set the stage, consider Figure 2. The four panels show annual contributions of the four components of the labor share to the annual change of the aggregate labor share. ${ }^{10}$ Clockwise from top left, these are real compensation, employment structure, relative prices and labor productivity. Simple averages of these four over the entire period are $1.7,0.2,-1.9$ and 0.04 , respectively: as suggested above, the short run changes are dominated by the contributions of real compensation and labor productivity. The series show a clear cyclical pattern. Contributions from real wages peak late in the cycle, those from labor productivity earlier. This is in line with standard findings, but not a focal point here. Obviously, real compensation exerts on average a positive influence, and labor productivity a negative one. The employment structure and the measure of relative prices is expected to contribute less, as changes across sectors roughly balance. ${ }^{11}$ The trajectory of the relative price

\footnotetext{
${ }^{10}$ Here and throughout the following discussion, it is critical to recognize the difference between component contributions, and a variable's rate of change. As the previous section laid out in detail, the contribution from one of the four components is composed of the variable's rate of change as well the appropriately chosen weight. Hence, a change in the variables contribution to the overall change in the labor share can be driven either by a change in the weights, or a change in the variable, or a combination of both.

${ }^{11}$ The means of these aggregate series are statistically significantly different from zero for compensation, employment and productivity, but not for relative prices.
} 
series suggests the importance of high inflation during the Seventies, and the positive impact of disinflation on the labor share in the subsequent decade. It further can be observed that the contribution from real compensation diminished over time, especially after 2000. The Great Moderation is not clearly discernible, with the first two decades of the neoliberal era showing strong real compensation volatility. However, a five-year moving average of this series has a negative trend, interrupted only late in the Nineties with the new economy bubble.

[Figure 3: Sectoral component contributions in manufacturing (MAN) and education and health services (EHS)]

Next, consider Figure 3, which reports details on manufacturing (MAN) and education and health services (EHS). These are highlighted here in order to emphasize the central role that structural changes away from manufacturing and towards services activities play in the decline of the aggregate labor share. ${ }^{12}$ The top two panels show annual contributions of these two sectors to the annual change in the aggregate labor share, the panels in the two rows below those of compensation and productivity and employment structure and relative prices, respectively.

Manufacturing is of course of particular interest. It features strong cyclicality, though the variance of its contribution appears to have decreased with deindustrialization. Panel (c) of Figure 3 shows a strong downward trend of the contribution of manufacturing's real compensation component across the entire post-war period, driven both by the sustained fall in the sector's employment share and the decline in real wage growth (see Figure 8 in Section 5). Further, Panel (e) documents the on average positive effects of both relative price and employment structure changes in manufacturing on the labor share. Of course, the relative price of manufacturing output has fallen dramatically. Moreover, and barely visible on this scale, the contribution of the employment component is on average negative (and significant) prior to 1979, and on average positive, and larger (and significant) after 1979: the collapse of the labor share in manufacturing during the neoliberal era - clearly taking off with the Great Moderation, and clearly preceding the "China shock"-implies that continued deindustrialization acts as a buffer on the aggregate decline in the labor share, as labor moves out of (into) a sector with a lower (higher) labor share.

Similarly, the sustained rise of the employment share of EHS, from about three percent in 1948 to more than fifteen percent after the Great Recession, buffers the overall decline in the labor share - since the latter averages $93 \%$ during the neoliberal era. Recall the discussion of the structural component in Section 3: the contribution of the employment component to the aggregate labor share is positive if the sectoral

\footnotetext{
${ }^{12}$ Further, it should be noted that the sum across the four sectoral components is equal to the total sectoral contribution. Analogously, the sum across all sectoral real compensation contributions is equal to the series shown in Panel (a) of Figure 2. More sectoral detail is shown in figures 7, 8 and 9 in Section 5, on which the discussion here repeatedly draws.
} 
labor share is larger than the aggregate and the employment share is rising, or if the sectoral labor share is smaller than the aggregate and the employment share is falling. The latter is true for manufacturing, the former for EHS. The contribution from the relative price component, in turn, is strongly negative. The well-known and sustained increases in the cost of healthcare provision and tuition at colleges and universities factor in here, and we will return to it below in a discussion of Baumol's disease. Although the sectoral contribution of EHS appears small, it is one of only two sectors' total contribution that is statistically significantly different from zero. The second aggregates professional and business services (PBS).

Let us now look at the two periods in more detail. As mentioned, we define the golden age as the period from 1948 to 1979, and the neoliberal era as the period from 1979 to 2017. The choice of the turning point can be controversial. The Great Moderation is thought to have begun only in 1985, whereas the golden age is often considered to have ended in 1973 . We choose 1979 as the cutoff because it (roughly) marks the turning point for several critical variables, from the manufacturing labor share to the wage-productivity gap for non-supervisory workers to the income share of the bottom fifty percent. It is furthermore a business cycle peak: November 1948 and January 1980 are the relevant NBER peak months, which we compare to the latest data available (2017). The aggregate labor share from the our sectoral data set saw an increase of $8.8 \%$ during the golden age, and a decrease of $-6.6 \%$ during the neoliberal era. A look back at Figure 1 indicates that the bulk of the increase occurred early in the golden age, and the bulk of the decrease late in the neoliberal era. Table 1 provides additional data based on Divisia index decompositions of the aggregate labor share from peak-to-peak of ten post-war US business cycles, both by four components and by fourteen sectors. While these data confirm the just mentioned pattern, and confirm manufacturing's critical weight in the decline during the neoliberal era, it comes as a bit of a surprise to see how large agriculture (AGR) factors in the early post-war rise of the labor share. The dominant component in this early period is the relative price change (though it is not statistically significant for the entire sample).

\section{[Figure 4: Sectoral contributions across "Golden Age" and "Neoliberal era"]}

\section{[Table 1: Contributions across business cycles]}

Figure 4 summarizes key results on the underlying patterns of structural change for the two periods. A variance decomposition in Table 2 and growth contributions in Table 3 provide related detail, on which the discussion here draws throughout. In a nutshell, the labor share rose during the golden age due to matching real wage and productivity gains across sectors, and fell during the neoliberal era due to real wage gains falling short, especially in manufacturing. The left column of panels in Figure 4 shows the golden age, the right the neoliberal era. The rop row reports 
total sectoral contributions, and the middle row sectoral component contributionsso that the sum across the four components in each sectoral bar in the middle panel is equal to the bar height in the top panel. The golden age exhibits a sense of balance. While some sectors contribute negatively, others contribute positively. Across sectors, contributions from the real compensation component are roughly proportional to that of productivity. In sharp contrast, the neoliberal era is marked by large negative contributions from MAN, WTR, INF and FIN, and large positive contributions from PBS and EHS. The middle panel shows that across sectors, contributions from labor productivity components exceed that of real compensation. This gap is especially dramatic in MAN, WTR, RTR, INF but as well FIN.

[Table 2: Variance decomposition of annual changes in the US labor share]

[Table 3: Growth contributions to annual changes in the US labor share]

The importance of the manufacturing sector for the overall change of the labor share cannot be overstated. The very large contribution from MAN to the aggregate labor productivity component in both periods - holding steady at forty six and forty four percent, respectively - is one side of this coin, and the difference in the sector's contribution to the aggregate real compensation component - falling from forty to twenty percent - is the other. (See Table 3 for details.) The bottom row of panels further focuses on these two critical components for all sectors. While sectoral differences are apparent during the golden age, with manufacturing as a strong outlier, the neoliberal era sees a dramatic increase in dispersion.

[Figure 5: Significance of sectoral component contributions]

Figure 5 provides additional insights. These scatterplots show the $t$-statistics of the means of sectoral component contributions in the two sub-periods. In each panel, the horizontal axis denotes the golden age, and the vertical axis the neoliberal era. As an example, consider Panel (a) on real compensation. The manufacturing sector's coordinates are $(10.3,3.9)$ : the former is the average of real compensation in MAN during golden age, relative to that series' standard error, the latter the same for the neoliberal era. The solid line has a slope of unity, and the square (with a dashed edge) indicates a five percent significance level for the shorter of the two samples. As is clear from visual inspection, all of the series' means are statistically significant, and all except other services (OTH) feature a lower average real compensation contribution during neoliberal era. Let us next consider the productivity contribution in Panel (c). First, productivity contributions across sectors are roughly similar across the two periods. However, the majority of the sectors featured a higher contribution from productivity growth towards the labor share during the golden age, in line with concerns about a protracted slowdown in technological change during the neoliberal era. Crucially for our discussion here, the productivity component from MAN, WTR and INF has a negative impact on the overall labor share, whereas 
EHS, the service sector already highlighted in Figure 3, exerts a positive impact - in other words, its productivity contribution is negative. ${ }^{13}$

The impact of relative price changes on the labor share differs starkly between "stagnant" Baumolian service sectors and the rest of the economy. Panel (d) of Figure 5 shows statistically significant dots for CON, PBS, AER, EHS and OTH, all in the negative quadrant and below the line; and for RTR, INF, MAN, WTR in the positve quadrant above the line. Put simply, stagnant service sectors experienced sustained relative price increases in both periods, and an acceleration of these trends in the neoliberal era. In contrast, manufacturing and some services often considered susceptible to productivity increases through the use of information technology, experienced sustained relative price decreases in both periods, and an acceleration thereof in the neoliberal era. It is of course no surprise that weak productivity performance and relative price increases are correlated, and vice versa. Lastly, consider Panel (b) on the impact of the employment structure. Data shown here for MAN and EHS complements the discussion above: manufacturing is the only sector whose employment component contribution to the labor share change switches from negative during the golden age to positive during neoliberal era. Again, stagnant service sectors stand out, with high, positive, and (in the case of AER and EHS) increasing contributions from the structural shifts in employment.

It is widely recognized that the overall change in the labor share is driven by withinsector changes, predominantly payrolls. The findings here suggest, however, that the nature of structural change is indeed quite strongly related to this overall change. At the center of it is a sustained decline of employment and a widening compensationproductivity gap in "dynamic" sectors on the one hand, and a sustained rise of employment without a compensation-productivity gap in "stagnant" sectors. In the following section, we discuss these results in the context of the seminal theories of Baumol and Lewis.

\section{Discussion: Baumol, Lewis and stagnation}

There is no shortage of explanations for the decline in the labor share in the recent literature. Karabarbounis and Neiman (2014) and Piketty (2014), among others, employ a neoclassical model with perfect competition in product and factor markets. Changes in factor income shares are possible if the elasticity of substitution between labor and capital differs from unity, and capital intensity changes. The latter can be

\footnotetext{
${ }^{13}$ We emphasize again that these data do not directly show real wage or productivity growth: a sector's component contribution in the decomposition is influenced by changing weights. Furthermore, the data in Figure 5 are $t$-statistics of the means of the respective series, reporting essentially whether the average is statistically different from zero. For comparison and clarity, see as well Table 4 , which shows sectoral labor productivity growth rates for the two periods. We will return to these data in the next section.
} 
caused by capital-augmenting technological change, or a decline in the price of new capital goods. ${ }^{14}$ Elsby et al. (2013) evaluate the predictions of the neoclassical model for the US economy and conclude evidence in its favor is rather weak. A shift to capital-intensive techniques of production is not the main cause behind the decline in the labor share; and neither is the decline in unionization of workers. Instead, these authors suggest that sectors with the largest import exposure have faced the biggest decline in the payroll share. Using data on commuting zones, Autor et al. (2013) reach a similar conclusion: trade-exposed labor markets have been affected negatively both in terms of employment and compensation. These findings appear to hold for other countries. Hogrefe and Kappler (2013) and Rada and Kiefer (2016) show similar results on the basis of econometric analysis for OECD countries. Unlike Elsby et al. (2013), the latter authors also find that union density remains a fairly robust correlate of the labor share even when including an index of globalization.

\section{[Figure 6: Structural change]}

Structural change remains a sideshow within this growing literature. This is in part due to the fact that the decomposition exercises do not identify structural change as a main source of change in the labor share. In other words, the labor share has not declined because workers moved to sectors with relatively lower labor shares. Rather, intra-industry dynamics dominate. Yet, a key observation is that structural change has indeed been important: dynamic sectors tend to shed labor, and stagnant sectors tend to absorb labor. (See the top row of panels in Figure 6.) The negative correlation between change in employment share and labor productivity growth persists throughout the entire period, with the qualification that the golden age saw five sectors with rising labor productivity that still absorbed labor, compared to only one - PBS - during the neoliberal era. The crucial observation here is that, from a structuralist perspective, the US economy has been less dynamic in the neoliberal era - sectors with rising labor productivity growth have generally been shedding jobs, while sectors with sluggish or declining labor productivity have been absorbing labor.

\section{[Table 4: Sectoral productivity growth and structural change]}

Table 4 complements the panels in Figure 6. As can be seen there, CON, PBS, OTH and TRW are the relatively larger sectors (as measured by employment shares), that have experienced a decline in labor productivity growth between the two periods. The majority of sectors had similar average annual productivity growth rates, implying that the shift in employment and value added towards stagnant sectors with relatively low or even negative labor productivity growth has contributed signifi-

\footnotetext{
${ }^{14}$ These scenarios can be augmented further by assuming labor heterogeneity and thus raising the possibility of skill-biased technological change, as well as capital-skill complementarities. Empirical support for these arguments is limited. Particularly problematic is the usually required assumption that the elasticity of substitution is larger than unity. Raval (2017) provides an in-depth discussion and concludes that evidence in favor is weak.
} 
cantly to the secular decline in productivity growth rates. ${ }^{15}$ Still, the key issue is that the labor share has declined due to real wage growth lagging productivity growth especially in the so-called progressive sectors.

A different picture emerges for the two periods when comparing the change in employment share and the sectors' relative labor productivity, see bottom row of diagrams in Figure 6. During golden age, labor moved to sectors with higher than average productivity levels; during neoliberal era, this relationship critically weakened and possibly reversed. The question is if this dynamic matters indeed for the evolution of the functional distribution of income, through channels not readily observed in the statistics obtained from the decomposition. It certainly has an effect on the growth of the economy if only through the use of workers in less productive activities.

Further, relative prices clearly matter: stagnant service sectors such as EHS, AER and OTH have seen a rise in relative prices, while manufacturing, information and trade sectors have seen a decline in relative prices. Are we, therefore, simply experiencing Baumol's disease? To evaluate this question, the first task is to briefly review the cost disease hypothesis. The original papers are Baumol and Bowen (1965) and Baumol (1967). The following discussion is based largely on the latter. First, assume, quite innocuously, that activities can be meaningfully categorized as either progressive $(p)$ or stagnant $(s)$, and that all costs aside of wages can be ignored. More importantly, assume further that real (consumption) wages across sectors equilibrate: in the progressive sector, nominal wages grow at the rate of productivity growth $r$ and prices remain constant; whereas in the stagnant sector, nominal wages grow at the same rate, while labor productivity remains unchanged. These changes in nominal unit costs are passed on to prices. If, in addition, demand for the stagnant sector's output is sufficiently price inelastic and income elastic; and as a result thereof or due to government intervention the output shares of the sectors remain constant, all labor will have to be transferred to the stagnant sector. As a consequence, the growth rate of the economy will fall to zero and relative (nominal

\footnotetext{
${ }^{15}$ Storm (2017) provides an extensive discussion of the root causes of secular stagnation of the US economy. Rising income inequality and labor market polarization, rather than a crisis in innovation, are identified as potential mechanisms behind the decline in aggregate productivity growth.
} 
unit labor) costs of the stagnant sector $\left(C_{s t} / C_{p t}\right)$ will rise without limit: ${ }^{16}$

$$
\begin{aligned}
& C_{p t}=\frac{W_{p t} L_{p t}}{Y_{p t}}=\frac{W e^{r t} L_{p t}}{b L_{p t} e^{r t}}=\frac{W}{b} \\
& C_{s t}=\frac{W_{s t} L_{s t}}{Y_{s t}}=\frac{W e^{r t} L_{s t}}{a L_{s t}}=\frac{W e^{r t}}{a}
\end{aligned}
$$

As Baumol points out, the cost disease does not require that wages increase with productivity. Two cases are possible. The one outlined above sees wages increasing with productivity in progressive sectors, and prices and wages increasing at that rate in stagnant sectors. The second possibility is that wages do not increase, but instead progressive sector prices decline in line with productivity. In either case, the aggregate real consumption wage increases with aggregate productivity and there are no distributive effects. Put simply, the critical assumption of Baumol's mechanism is that the labor share is constant. ${ }^{17}$

Revisiting his ideas, Baumol (2012) credits a letter from Joan Robinson to him to emphasize the latter point. Surely, she assured him, the cost disease will not be the end of the world, if there is at least some productivity growth in stagnant activities. Most importantly, he concluded, society would always be able to afford the output of these activities, since aggregate income is growing at the rate of productivity growth in the dynamic sectors. In other words, education, health and other personal services are societally affordable if the labor share remains constant. We know of course that this is not the case.

An alternative narrative builds on Lewis (1954), Kalecki (1976) and Kaldor (1978). Lewis's dual economy is characterized by the co-existence of modern and subsistence economic activities. In the Lewis model, marginal labor productivity in the latter is zero, so that transfer of labor to urban, modern employment does not change subsistence agricultural output or costs. In turn, the real wage in terms of consumption goods of urban workers does not need to rise. Growth and accumulation are therefore facilitated by a steady supply of cheap labor and the corresponding super-profits. Only once the rural surplus labor is exhausted do costs and prices change, and urban real wages rise. At this turning point, the economy has developed in the sense that production is labor-constrained. Structuralist versions of this story emphasize the role of demand. Specifically, demand for modern sector output needs

\footnotetext{
${ }^{16} \mathrm{~L}$ is employment, $Y$ is real valued added or output, $a$ and $b$ are initial levels of labor productivity in the stagnant and progressive sector, respectively. Initial $W$ is fixed and the same for both sectors: Baumol assumes equilibration of wage levels. The data, in contradiction, show a persistent though declining premium of dynamic sector wages. Introducing that assumption would not change the nature of the cost disease, as long as dynamic and stagnant sector wages grow at the same rate.

${ }^{17}$ Indeed, Baumol (1967, p. 417) asserts, likely influenced by the prevailing zeitgeist, that "[s]ince organized labor is not slow to learn of increases in its productivity it is likely to adjust its wage demands accordingly." Note that in the original example, and if costs equal prices, the labor share is equal to unity. If other input costs are considered, this would of course not be the case.
} 
to be sufficiently strong to lead to absorption of rural surplus labor, all the while the sector's productivity increases through the Kaldor-Verdoorn channel, and the economy's average productivity increases with that and the compositional shifts.

Let us consider this in the context of the data discussed here. For the sake of clarity, we abstract from primary activities. Four dynamic sectors feature consistently high labor productivity growth contributions: MAN, WTR, INF, and FIN; and four stagnant sectors feature consistently low (if positive) or even negative contributions: TRW, EHS, AER, and OTH. (RTR and PBS are borderline cases.) All sectors of the first set feature falling employment and labor shares at least in the second period under analysis; all except OTH feature rising employment shares over the same period and either rising or stable labor shares (see Figure 7 and 8 below). These sectoral labor shares measure product wages relative to labor productivity: since nominal wages grow (roughly) at the same rates, the strong relative price increases in the stagnant sectors suggest slower real product wage growth there than in progressive sectors. Despite this, labor shares rose due to very anemic labor productivity performance.

\section{[Figure 7: Sectoral labor shares]}

\section{[Figure 8: Sectoral value added and employment shares]}

In summary, Baumol's disease is apparent, but with crucial qualifications à la Lewis. Clearly, employment shifts towards stagnant activities, and (widely documented elsewhere) the rate of labor productivity growth has slowed. Clearly, there is upward pressure in relative prices in the stagnant sectors. At the same time, this cannot be due to the pressure of dynamic sector wages rises in line with productivity growth. Specifically, labor shedding coincides (after 1979) with the opening of a significant gap between the growth rates of real consumption wages and labor productivity in progressive sectors. Structural change towards stagnant sectors has thus led to a buildup of labor reserves in jobs with relatively low levels of nominal wages. Accordingly, and due to institutional changes during the last several decades, bargaining power of labor remaining in progressive sectors is critically weakened. Baumol, as quoted above (see fn. 17), thus appears half-right: "[while] organized labor is not slow to learn of increases in its productivity, it is [now much less able] to adjust its wage demands accordingly."

\section{Conclusion}

The key contribution of this paper lies in the presentation of a Divisia index decomposition of the change in the US post-war labor share into its four principal components in fourteen sectors. Our findings confirm prior results. Specifically, the change in the aggregate labor share is dominated by within-sector changes, and by the dramatic decline of the labor share in manufacturing. Our findings also critically 
augment prior results, primarily through the rich detail on the contributions from real compensation, employment structure, labor productivity and relative prices.

First, the aggregate measure of the labor share, based on our sectoral data set of US private economic activity excluding real estate, shows a strong increase during the golden age, and a decline thereafter. Second, the contribution from real compensation growth across all sectors (except other services) has declined markedly from golden age to neoliberal era. This result would likely be exacerbated if the data were to exclude stock options, or more generally, the top sliver of the compensation distribution: our results are a quite cautious estimate of the decline in the labor share. At the same time, the contribution from labor productivity has changed much less. Third, observed patterns of structural change are closely related to the change in the aggregate labor share: dynamic, high productivity growth activities with relatively high real wages but low labor shares are shedding labor, whereas stagnant, low productivity growth activities with low real wages and high labor shares are absorbing it. This trajectory buffers the overall decline of the labor share.

The corresponding decline in the aggregate growth rate of labor productivity raises further questions. To what extent and in what manner are structural change, inequality and the stagnation of growth connected? Our preliminary assessment, outlined in the previous section, is that it would be simply wrong to view these developments as the natural occurrence along a trajectory of tertiarization. Baumol's disease can be characterized as speaking to three distinct issues: predictions, the proposed mechanism, and the implications for stagnation. Our data appears to confirm the predictions: employment shifts towards stagnant activities, their relative prices rise, and aggregate labor productivity growth decreases. However, a competitive market for homogenous labor as proposed in Baumol (1967) is not what is driving these trends: wage levels do not equilibrate, and sectoral real consumption wages do not grow in line with aggregate labor productivity growth. The observed patterns instead suggest, first, the importance of labor market institutions, with a rise of labor share in golden age and decline thereafter. Second, the critical feature of a dual economy is that dynamic sector real wages lag behind productivity growth since surplus labor, mostly involuntarily parked in stagnant activities with lower real wages, is always available. This very fact renders trends "reverse-Lewis," rather than simply Baumolian.

An important and here unadressed question is how precisely the observed structural change, the decline in the labor share and secular stagnation interrelate. As Robinson emphasized to Baumol, lower aggregate growth does not need to be a problem, as long as crucial services remain affordable for the entire population. This is of course not the case, and future research should seek to address these broader questions. 


\section{References}

Alvaredo, F., Chancel, L., Piketty, T., Saez, E., and Zucman, G. (2018). The elephant curve of global inequality and growth. American Economic Review: Papers and Proceedings, 108:103-108.

Ang, B. (2004). Decomposition analysis for policymaking in energy: Which is the preferred method? Energy Policy, 32(9):1131 - 1139.

Autor, D., Dorn, D., Katz, L. F., Patterson, C., and Reenen, J. V. (2017). The fall of the labor share and the rise of superstar firms. Working Paper 23396, National Bureau of Economic Research.

Autor, D. H., Dorn, D., and Hanson, G. H. (2013). The china syndrome: Local labor market effects of import competition in the united states. American Economic Review, 103(6):2121-68.

Barrales, J. and von Arnim, R. (2017). Longer-run distributive cycles: Wavelet decompositions for the US, 1948-2011. Review of Keynesian Economics, 5:196217.

Baumol, W. J. (1967). Macroeconomics of unbalanced growth: The anatomy of urban crisis. The American Economic Review, 57(3):415-426.

Baumol, W. J. (2012). The Cost Disease: Why Computers Get Cheaper and Health Care Doesn't. Yale University Press.

Baumol, W. J. and Bowen, W. G. (1965). On the performing arts: The anatomy of their economic problems. The American Economic Review, 55(1/2):495-502.

Bivens, J., Gould, E., Mishel, L., and Shierholz, H. (2014). Raising America's pay: Why it's our central economic policy challenge. EPI Briefing Paper 378.

Böckerman, P. and Maliranta, M. (2012). Globalization, creative destruction, and labour share change: Evidence on the determinants and mechanisms from longitudinal plant-level data. Oxford Economic Papers, 64(2):259-280.

Dietzenbacher, E. and Los, B. (1998). Structural decomposition techniques: Sense and sensitivity. Economic Systems Research, 10(4):307-324.

Diewert, W. E. (2010). On the Tang and Wang decomposition of labour productivity growth into sectoral effects. In et al, W. D., editor, Price and productivity measurement, volume Volume 6, chapter 4, pages 67-76. Trafford Press.

Dumagan, J. C. (2002). Comparing the superlative Törnqvist and Fisher ideal indexes. Economics Letters, 76(2):251 - 258. 
Duménil, G. and Lévy, D. (2015). Neoliberal managerial capitalism. International Journal of Political Economy, 44(3):71-89.

Elsby, M. W. L., B., H., and Sahin, A. (2013). The decline of the us labor share. Brookings Papers on Economic Activity, 2:1-63.

Gordon, R. J. and Dew-Becker, I. (2008). Controversies about the rise of American inequality: A survey. Working Paper 13982, National Bureau of Economic Research, Working Paper 13982.

Herrendorf, B., Rogerson, R., and Valentinyi, A. (2014). Chapter 6 - growth and structural transformation. In Aghion, P. and Durlauf, S. N., editors, Handbook of Economic Growth, volume 2 of Handbook of Economic Growth, pages 855 - 941. Elsevier.

Hogrefe, J. and Kappler, M. (2013). The labour share of income: Heterogeneous causes for parallel movements? The Journal of Economic Inequality, 11(3):30319 .

IMF (2017). Understanding the downward trend in labor income shares. Technical report, IMF.

Kaldor, N. (1978). Further Essays on Economic Theory. Holmes \& Meier, New York.

Kalecki, M. (1976). Essays on developing economies. Humanities Press.

Karabarbounis, L. and Neiman, B. (2014). The global decline of the labor share*. The Quarterly Journal of Economics, 129(1):61-103.

Kruger, J. J. (2008). Productivity and structural change: a review of the literature. Journal of Economic Surveys, 22(2):330-363.

Lazonick, W. (2015). When managerial capitalism embraced shareholder-value ideology. International Journal of Political Economy, 44(3):90-99.

Lewis, W. (1954). Economic development with unlimited supplies of labor. Manchester School of Economic and Social Studies, 22:139-91.

Marglin, S. A. and Schor, J. (1992). Golden Age of Capitalism: Reinterpreting the Postwar Experience. Oxford: Clarendon Press Oxford.

Piketty, T. (2014). Capital in the Twenty-First Century. Harvard University Press.

Rada, C. and Kiefer, D. (2016). Distribution-utilization interactions: A race-to-thebottom among oecd countries. Metroeconomica, 67(2):477-498. 
Raval, D. (2017). What's wrong with Capital in the Twenty-First Century's Model?, pages 75-98. Harvard University Press.

Rognlie, M. (2015). Deciphering the fall and rise in the net capital share: Accumulation or scarcity? Brookings Papers on Economic Activity, 2:1-54.

Storm, S. (2017). The new normal: Demand, secular stagnation and the vanishing middle-class. Working Paper 55, Institute for New Economic Thinking.

Taylor, L. and Ömer, O. (2018). Race to the bottom: Low productivity, market power, and lagging wages. Institute for New Economic Thinking Working Paper.

Temin, P. (2017). The Vanishing Middle Class. Prejudice and Power in a Dual Economy. MIT Press.

van Neuss, L. (2019). The drivers of structural change. Journal of Economic Surveys, 33(1):309-349. 


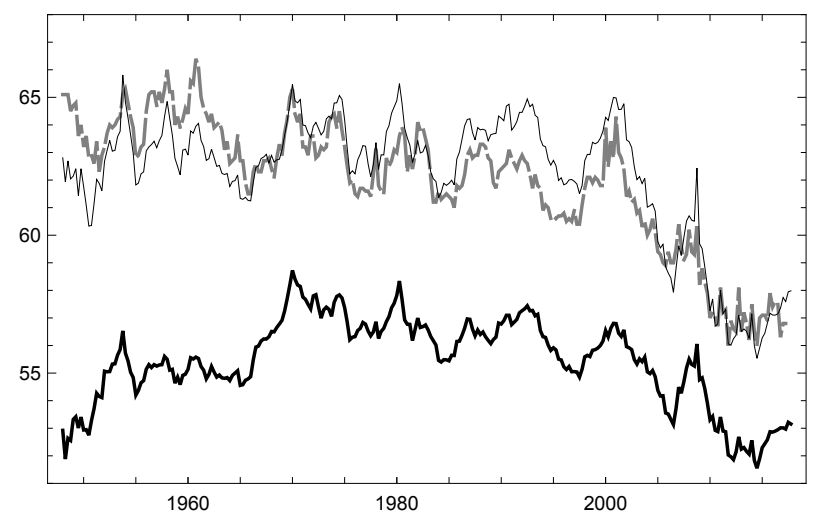

(a) BLS headline \& alternatives

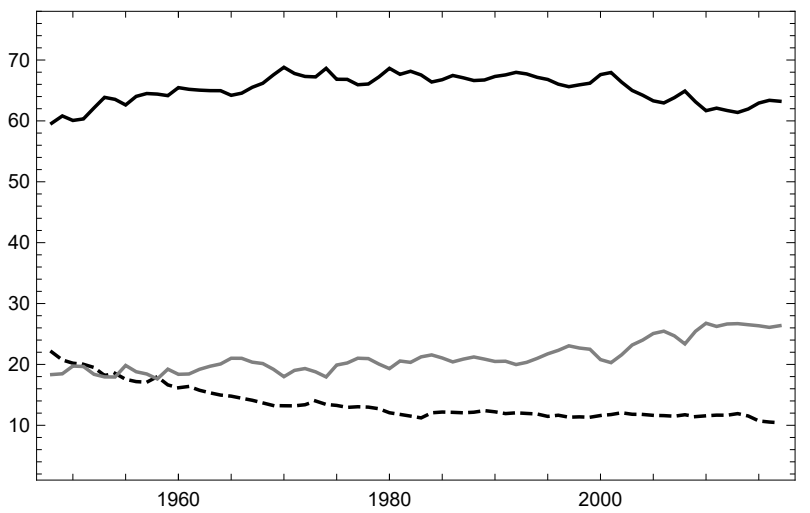

(c) Component shares of value added

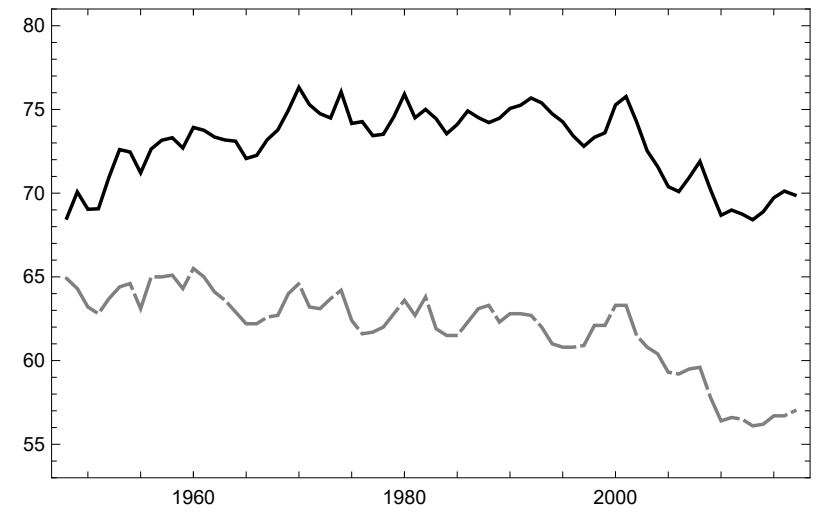

(e) BLS headline vs. our measure

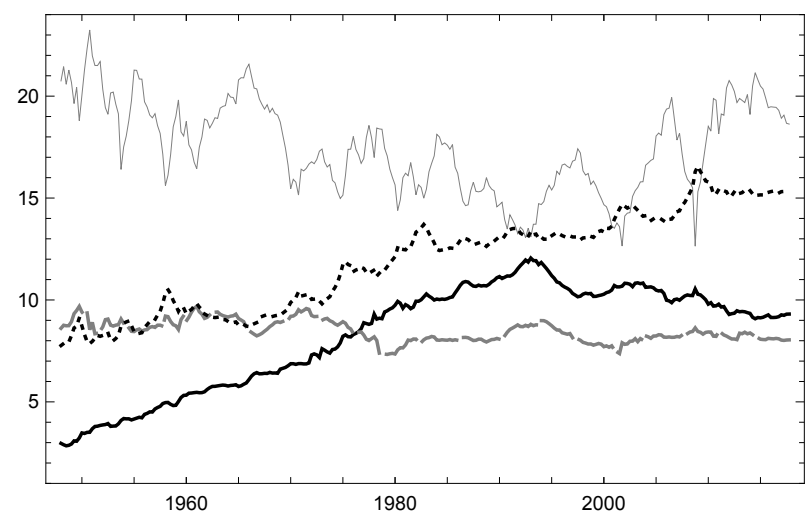

(b) Corporate payroll share

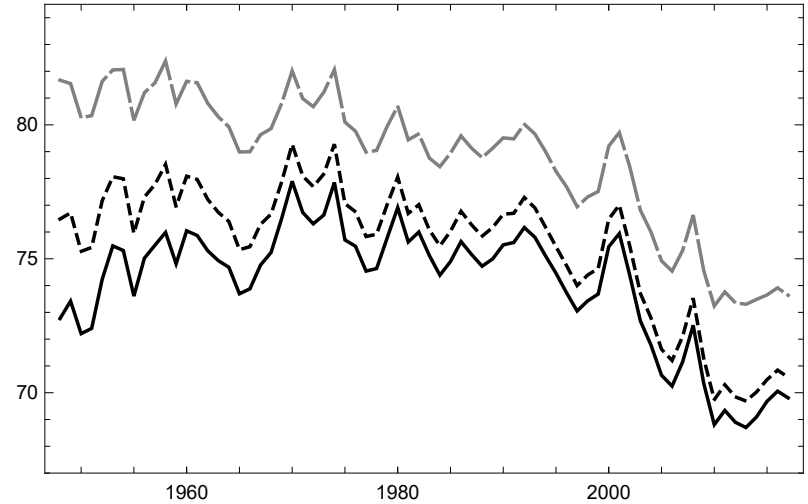

(d) Different labor share definitions

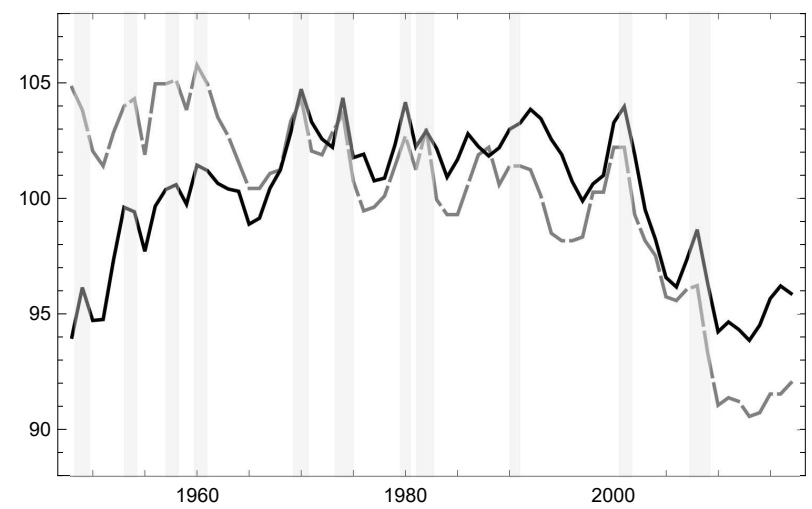

(f) Same as (c); relative to sample mean

Figure 1: Aggregate labor share. The figure shows different measures of the aggregate labor share. Panel (a) reports three series: the BLS headline measure of the labor share in the nonfarm business sector (gray dashed); compensation relative to gross value added in the corporate sector (gray, black); and the share of compensation for all employees (private and government) relative to gross domestic income (black). Panel (b) provides further detail on flows relative to gross value added in the corporate sector. From the top, in 2017, these are net operating surplus (gray thin); depreciation (black dotted); supplements to wages and salaries (black); and taxes on production and income (gray dashed). The bottom four panels illustrate the aggregate labor share based on the sectoral data set used here. Panel (c) shows component shares of value added. Panel (d) shows different treatments of non-corporate income. The black solid line is our preferred measure, which is shown in Panel (e) together with the BLS headline labor share. Panel (f) shows the same two series relative to their sample means. 


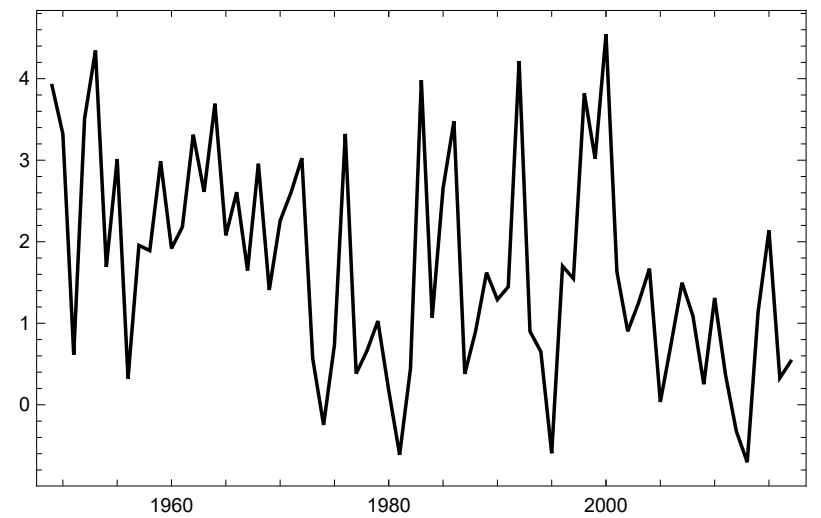

(a) Real compensation

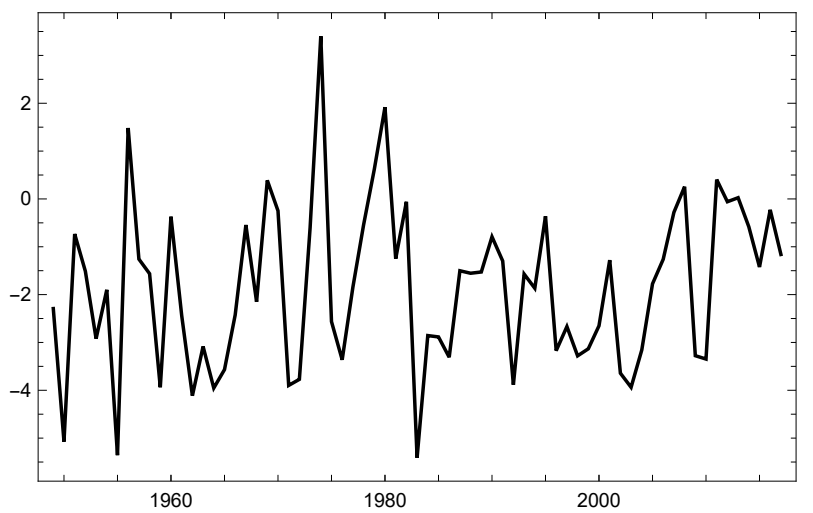

(c) Labor productivity

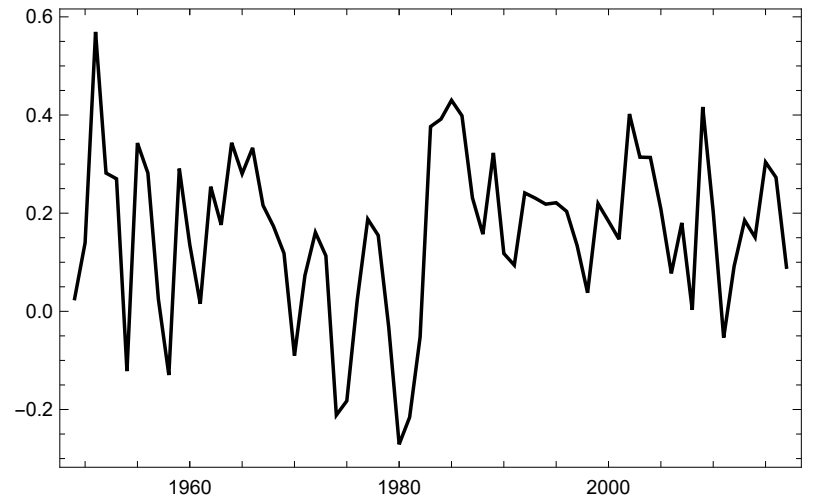

(b) Employment structure

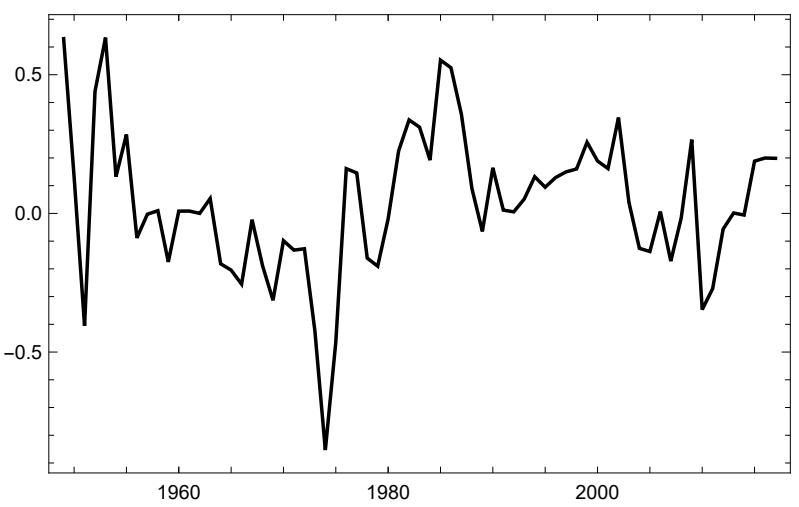

(d) Relative prices

Figure 2: Component contributions to aggregate labor share change: The figure summarizes results from the Divisia index decomposition of the labor share measure. The four panels list component contributions to the aggregate labor share change over the post-war period. The sum across the four components provides the annual percentage change in the labor share. 


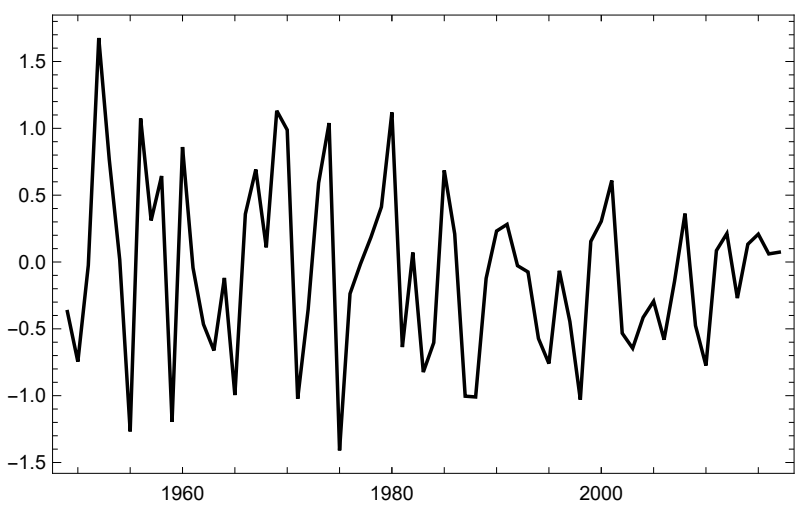

(a) MAN: Total sectoral contribution

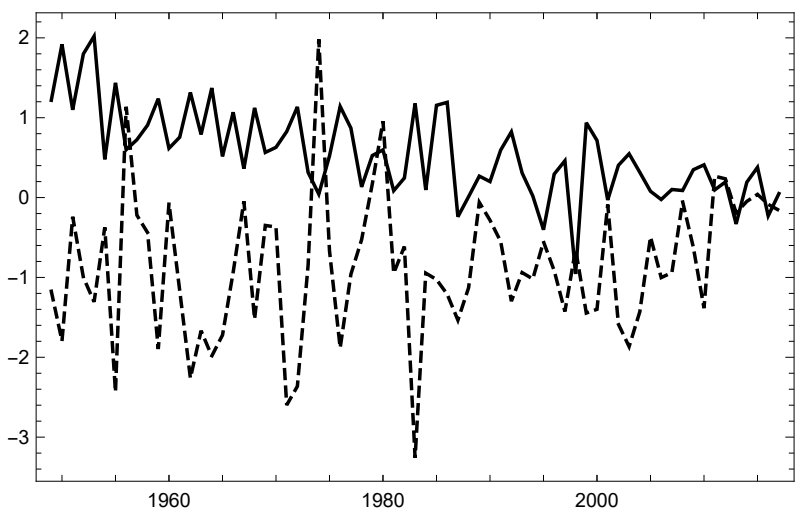

(c) MAN: Compensation \& productivity

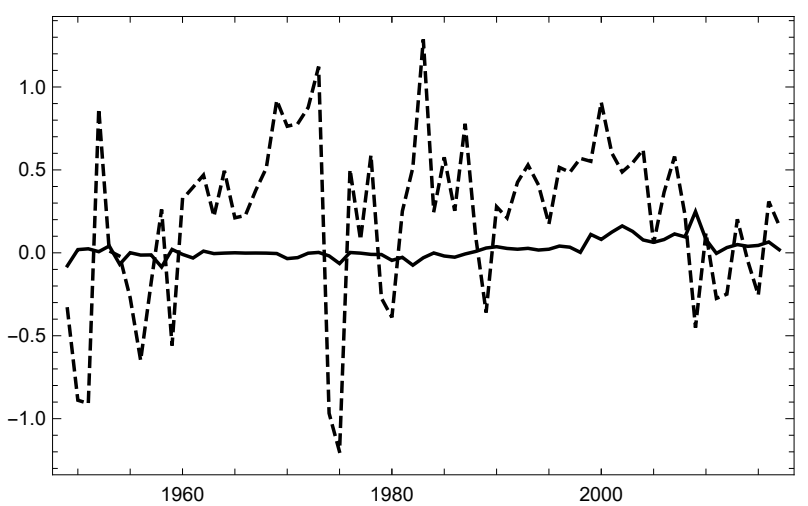

(e) MAN: Employment \& prices

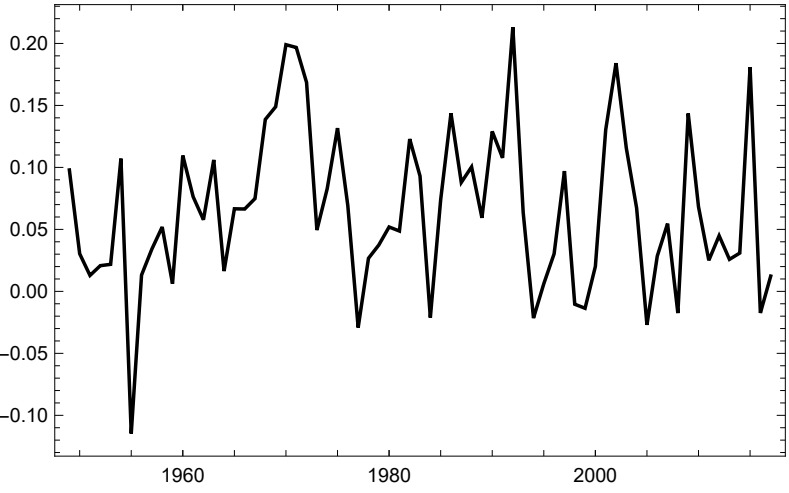

(b) EHS: Total sectoral contribution

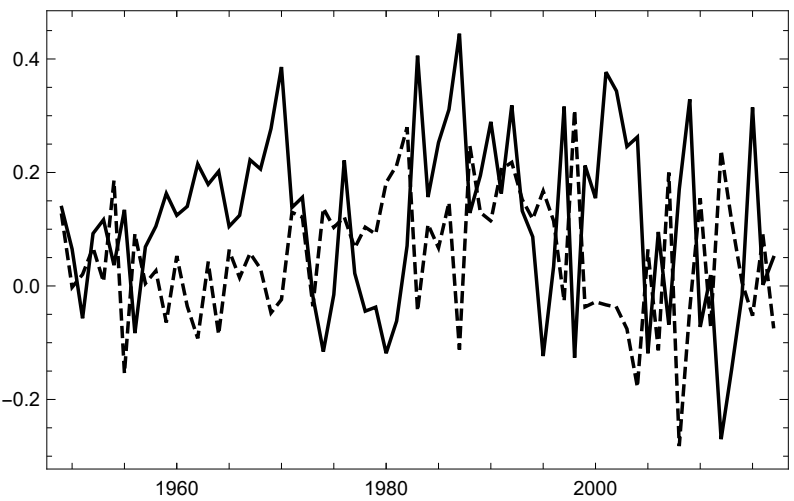

(d) EHS: Compensation \& productivity

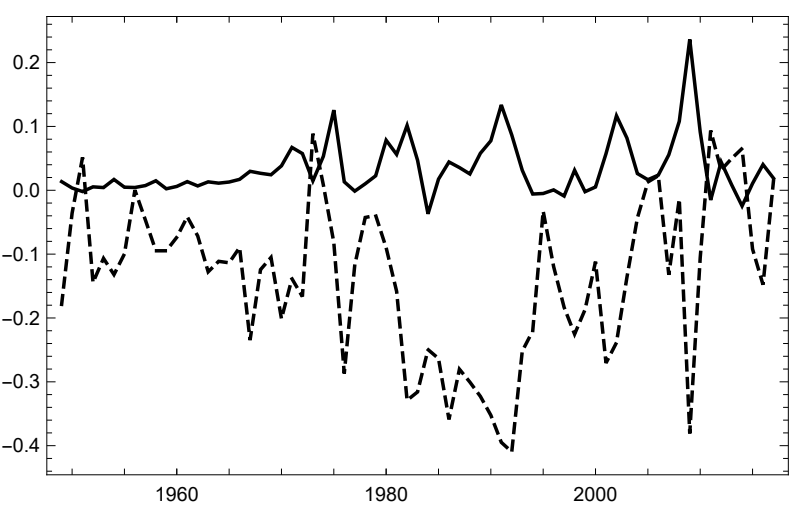

(f) EHS: Employment \& prices

Figure 3: Sectoral component contributions in manufacturing (MAN) and education and health services (EHS): The figure provides detailed results of the Divisia index decomposition for two selected sectors. The top panels show total sectoral contributions, middle panels contributions of real compensation (solid) and labor productivity (dashed), and bottom panels contributions of employment structure (solid) and relative prices (dashed). The sum across the four sectoral component contributions equals the total contribution in the top panels. 


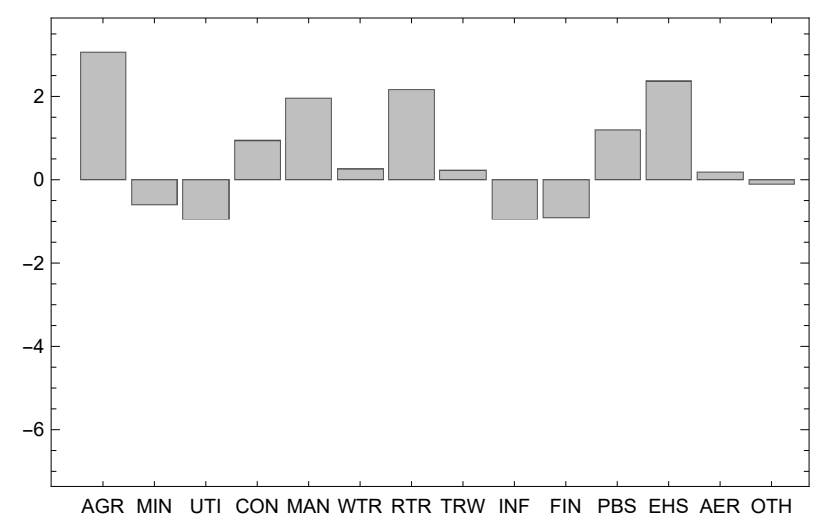

(a) Golden Age: Total

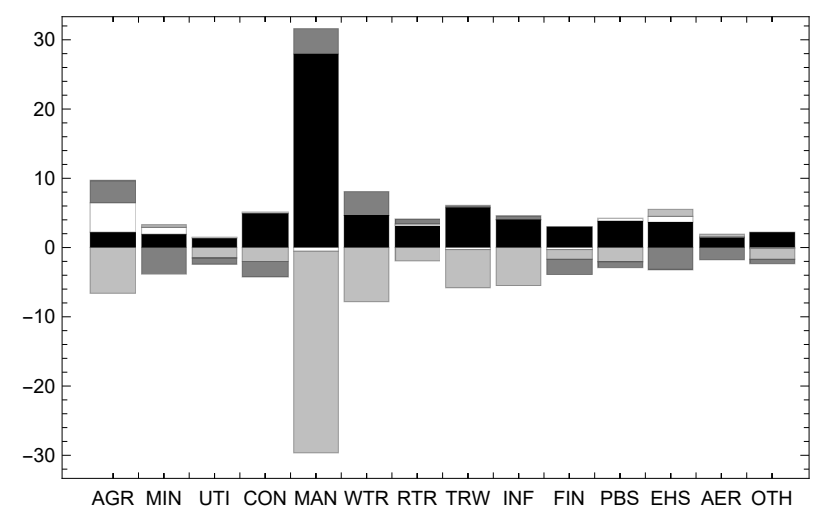

(c) Golden Age: Components

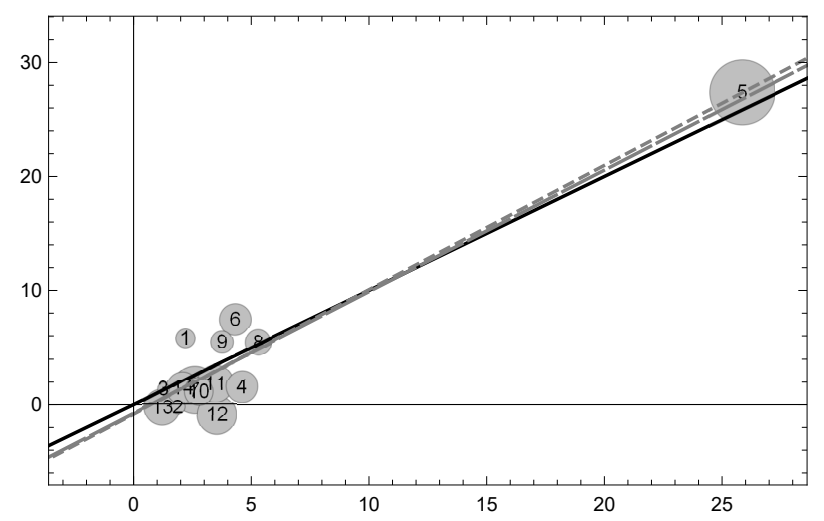

(e) Golden Age

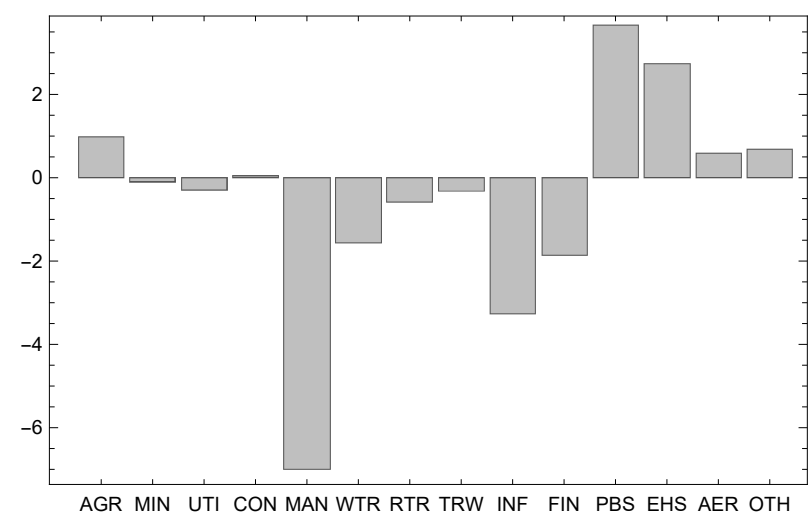

(b) Neoliberal Era: Total

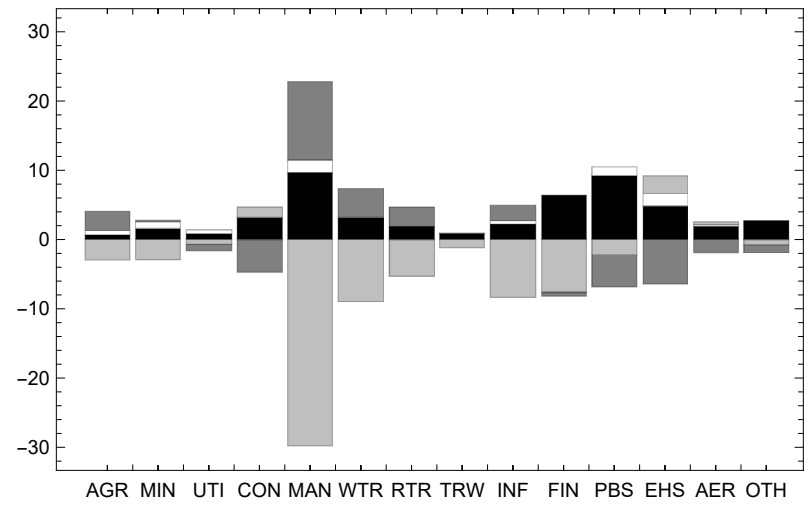

(d) Neoliberal Era: Components

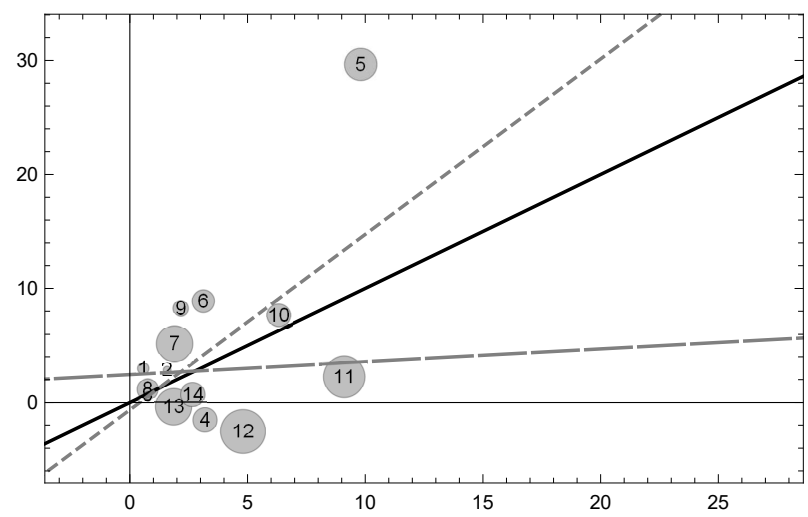

(f) Neoliberal Era

Figure 4: Sectoral contributions across "Golden Age" and "Neoliberal era": The top two panels show total sectoral contributions, and the middle two panels sectoral component contributions: real compensation is black; employment structure white; labor productivity light gray and relative prices dark gray. The bottom row focuses on the sectoral contributions of real compensation (horizontal axis) vs. labor productivity (vertical axis). Bubble sizes represent employment share at the end of the respective period. The solid line has a slope of 1 , the dashed line is an OLS regression, and the long-dashed line an OLS regression excluding manufacturing (5). 


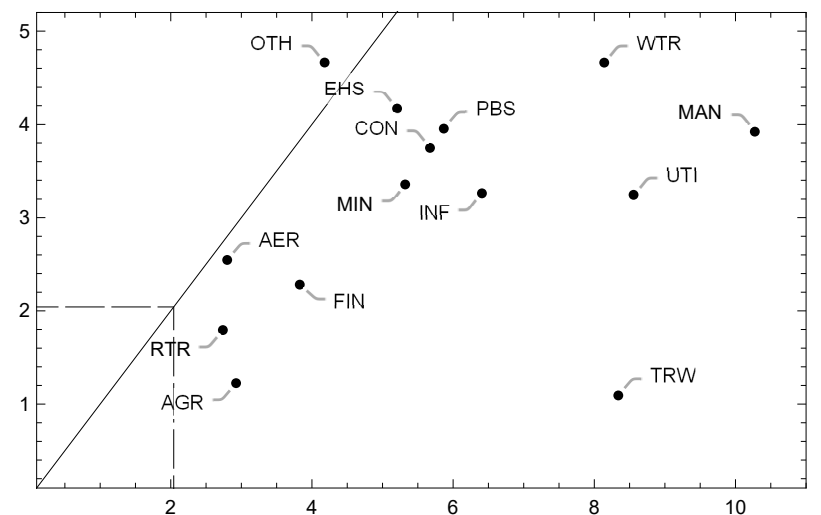

(a) Real compensation

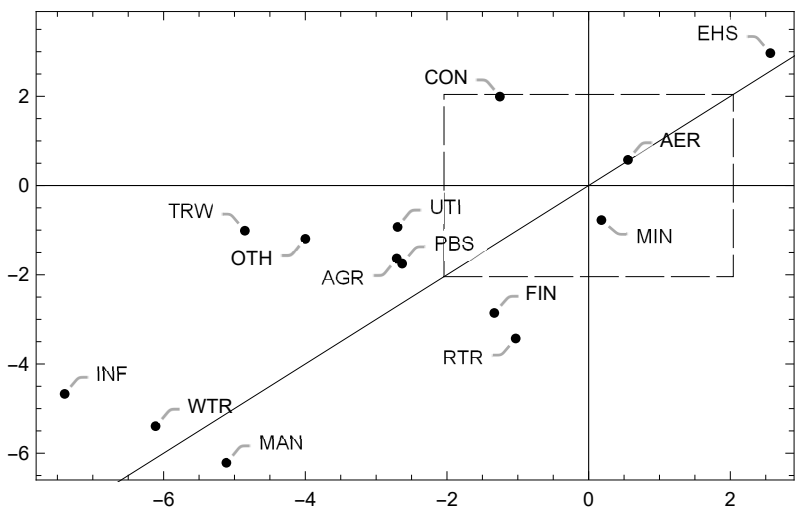

(c) Labor productivity

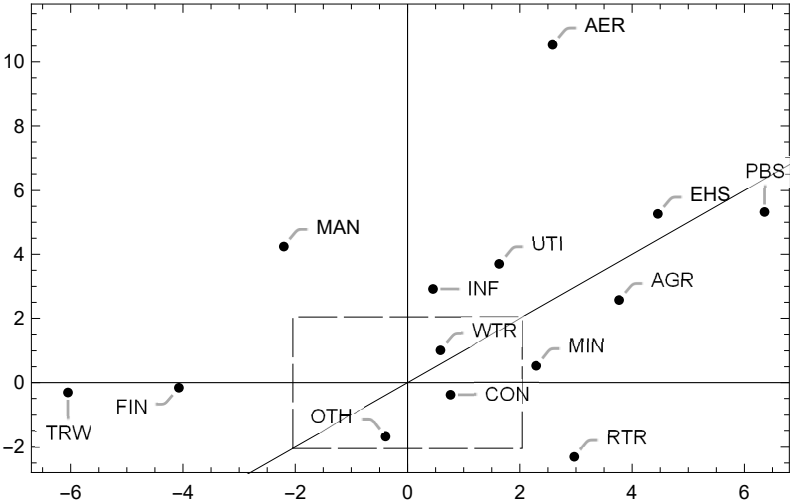

(b) Employment structure

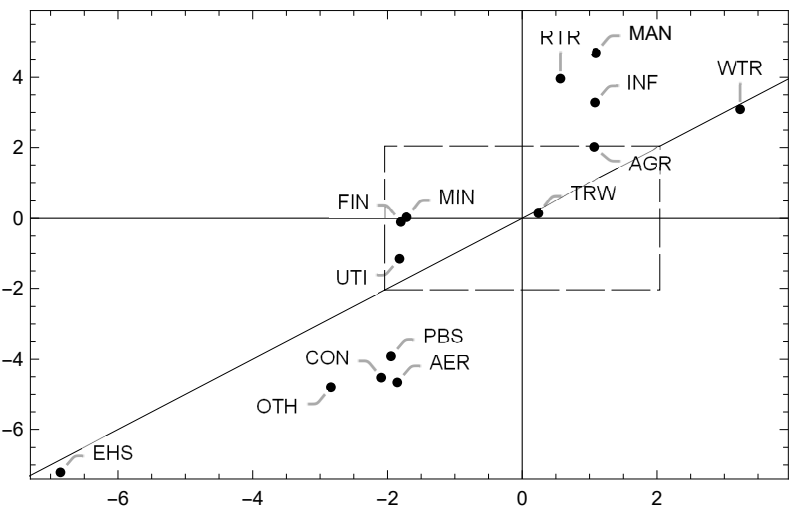

(d) Relative prices

Figure 5: Significance of sectoral component contributions. Each panel reports t-statistics for the means of one of the four components of all fourteen sectors. The horizontal axis shows the golden age (1948-1979), the vertical axis the neoliberal era (1979-2017). The solid line has a slope of unity; the dashed square denotes the threshold for statistical significance at the five percent level for the shorter sample of the golden age, with $d f=30$. 


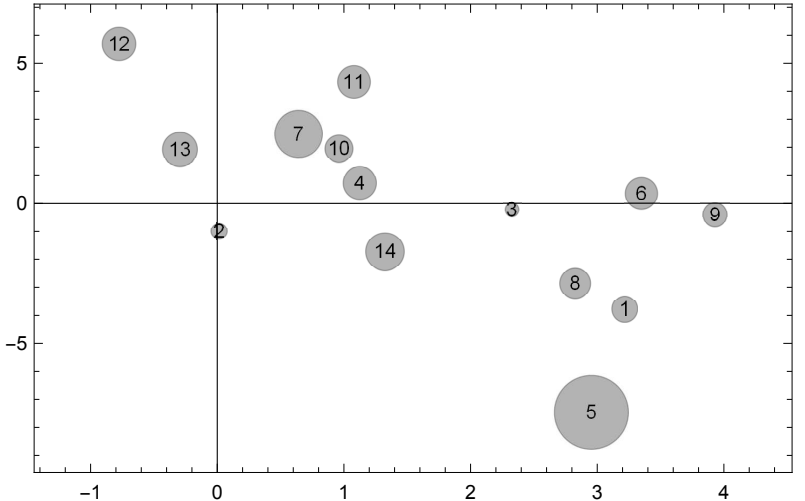

(a) Golden Age, 1948-1979

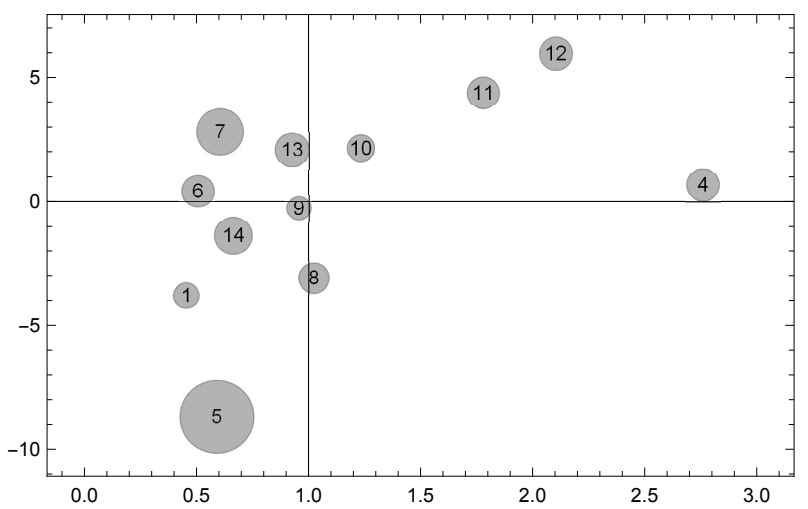

(c) Golden Age, 1948-1979

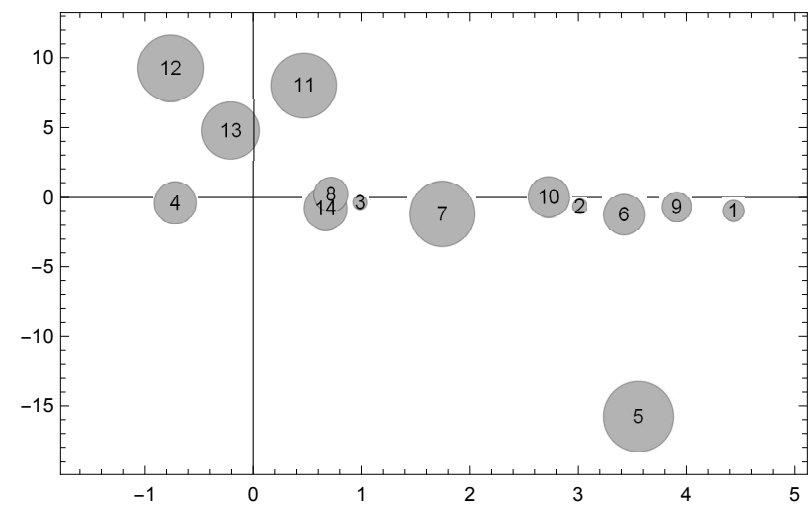

(b) Neoliberal Era, 1979-2017

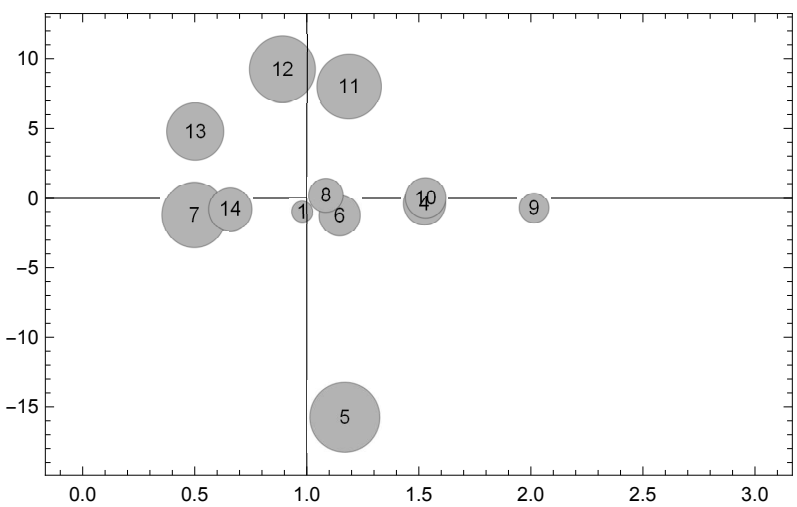

(d) Neoliberal Era, 1979-2017

Figure 6: Structural change: The figure illustrates patterns of structural change in the US post-war period. Panel (a) and (b) depict the average annual growth of labor productivity (horizontal axis) vs. the change in the sectoral employment share in percentage points. Panel (c) and (d) show average relative labor productivity on the horizontal axis, against the change in the sectoral employment share in percentage points. 

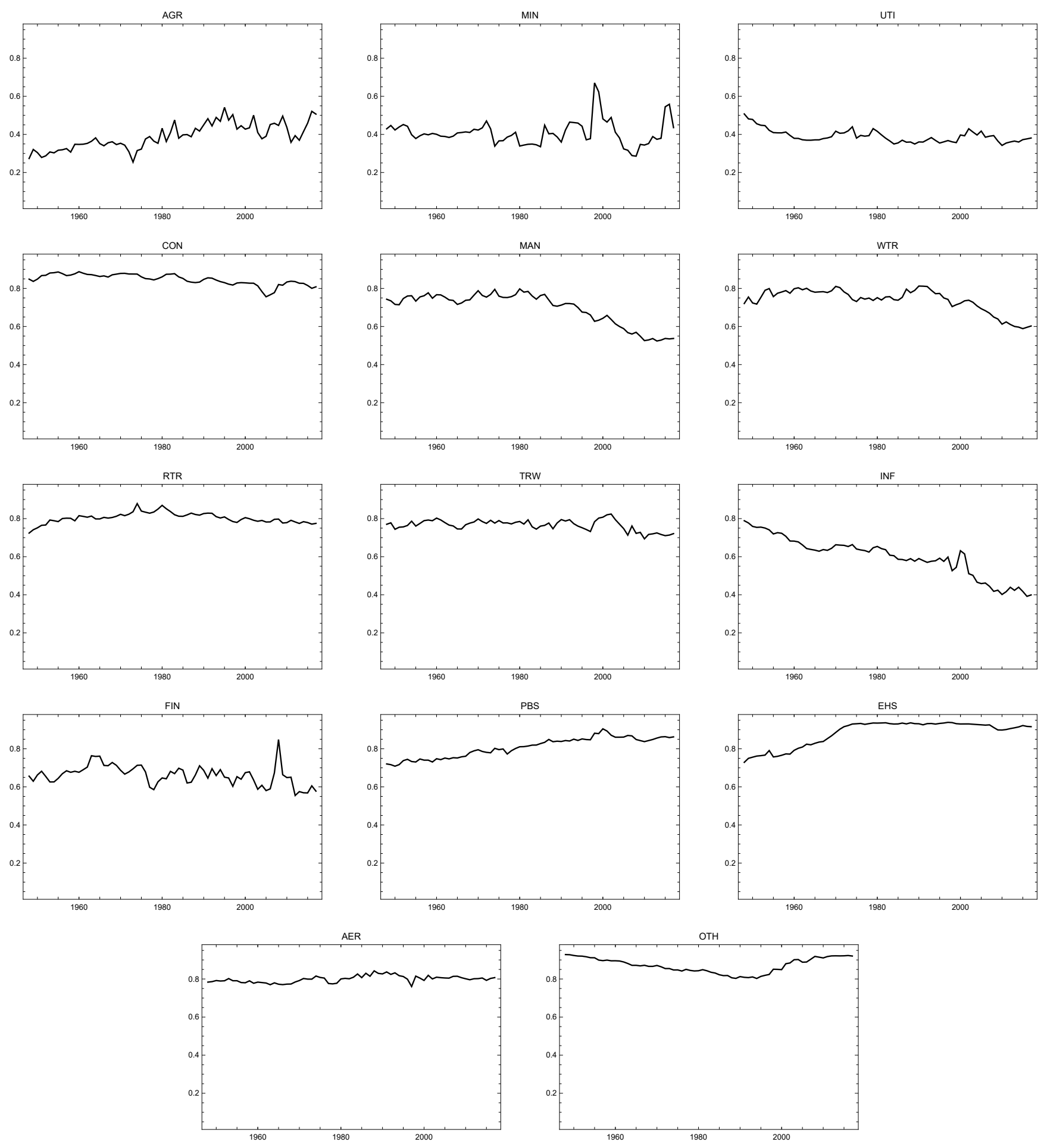

Figure 7: Sectoral labor shares: The fourteen panels of this figure show sectoral labor shares. 

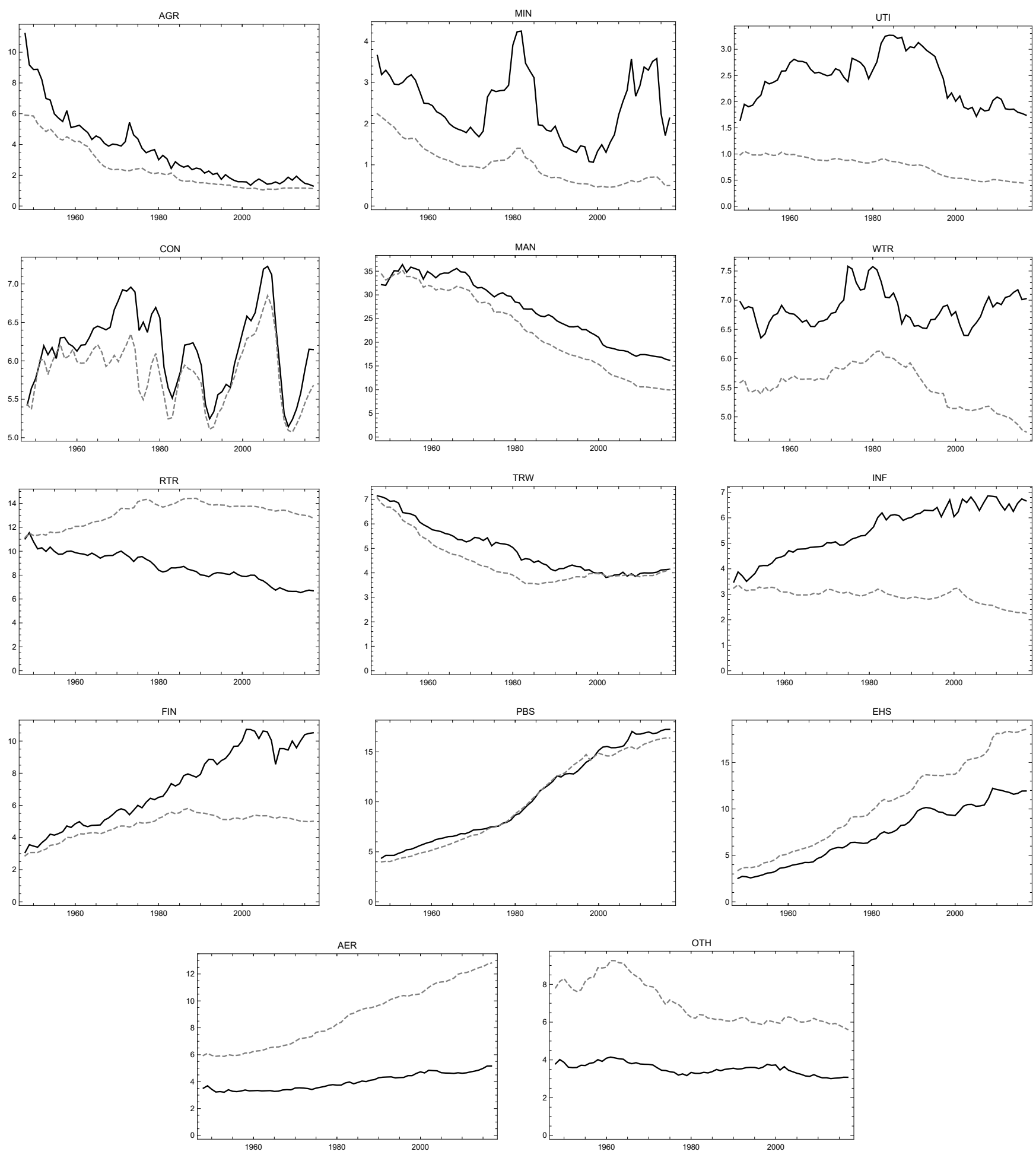

Figure 8: Sectoral value added and employment shares: The fourteen panels of this figure show sectoral shares of value added (black) and employment (gray dashed). 

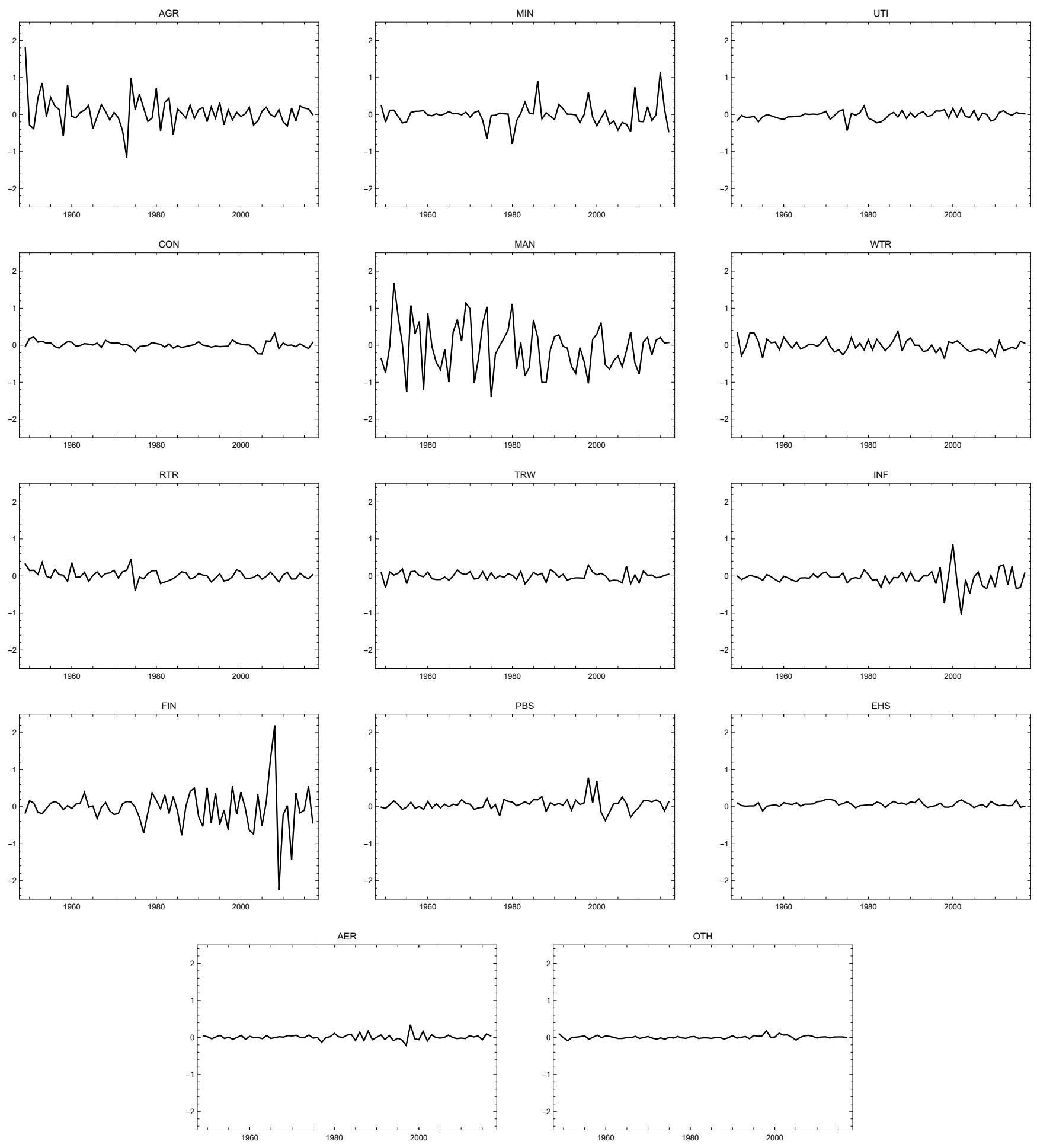

Figure 9: Sectoral contributions to aggregate labor share change: The fourteen panels of this figure show sectoral contributions to the aggregate change in the labor share measure. 


\begin{tabular}{r|rrrrrrrrrr}
\hline \hline & $48-52$ & $52-56$ & $56-59$ & $59-69$ & $69-73$ & $73-79$ & $79-89$ & $89-00$ & $00-07$ & $07-17$ \\
\hline Total & 3.6 & 2.4 & 0.1 & 3.1 & -0.6 & 0.1 & -0.1 & 1.1 & -5.7 & -1.5 \\
\hline Comp. & 11.6 & 9.5 & 6.8 & 24.8 & 8.5 & 5.9 & 13.8 & 22.4 & 7.6 & 6.1 \\
Empl. & 1.2 & 0.9 & 0.2 & 2.1 & 0.3 & 0.1 & 2. & 2.2 & 1.7 & 2. \\
Prod. & -9.9 & -8.9 & -6.8 & -22.5 & -8.7 & -4.8 & -19. & -24.9 & -15.2 & -9.4 \\
Pric. & 0.7 & 1. & -0.2 & -1.2 & -0.7 & -1.2 & 3.1 & 1.4 & 0.1 & -0.2 \\
\hline AGR & 1.5 & 1.5 & 0.4 & 0. & -1.7 & 1.5 & 0.7 & 0.2 & 0. & 0.1 \\
MIN & 0.3 & -0.4 & 0.3 & 0.2 & -0.1 & -0.6 & 0.3 & 0.3 & -1.3 & 0.8 \\
UTI & -0.3 & -0.3 & -0.2 & -0.2 & 0. & 0. & -0.7 & 0.4 & 0. & 0. \\
CON & 0.5 & 0.2 & 0. & 0.3 & 0.2 & -0.2 & -0.1 & 0.1 & -0.3 & 0.2 \\
MAN & 0.6 & 0.5 & -0.3 & 0.9 & 0.2 & 0. & -2.2 & -2. & -2. & -0.4 \\
WTR & 0.3 & 0.2 & 0. & 0.2 & -0.1 & -0.3 & 0.5 & -0.6 & -0.5 & -0.7 \\
RTR & 0.7 & 0.5 & -0.1 & 0.5 & 0.4 & 0.1 & -0.3 & 0. & -0.1 & -0.2 \\
TRW & -0.1 & 0.2 & 0.1 & 0. & 0.1 & -0.1 & 0. & 0.2 & -0.2 & -0.2 \\
INF & -0.1 & -0.1 & -0.3 & -0.4 & 0. & -0.1 & -0.8 & 0.2 & -1.9 & -0.6 \\
FIN & -0.1 & 0. & 0. & 0.1 & -0.2 & -0.7 & 0.6 & -0.7 & -0.1 & -1.5 \\
PBS & 0.2 & 0.1 & -0.1 & 0.6 & 0. & 0.3 & 1. & 2.2 & -0.2 & 0.4 \\
EHS & 0.2 & 0. & 0.1 & 0.9 & 0.6 & 0.3 & 0.8 & 0.6 & 0.6 & 0.5 \\
AER & 0. & 0. & 0. & 0.1 & 0.1 & -0.1 & 0.3 & -0.1 & 0.2 & 0.1 \\
OTH & 0. & 0. & 0.1 & 0. & -0.1 & -0.1 & -0.1 & 0.3 & 0.2 & 0.1 \\
\hline
\end{tabular}

Table 1: Component and sectoral contributions across business cycles: The table summarizes results of the Divisia index decomposition for ten US post-war business cycles. The ten periods represents peak-to-peak comparisons of NBER recession dates. In two cases (1948 and 1973), the peak falls into November of the year listed, otherwise the monthly peak occurs in the subsequent year. The peak-to-peak period from Jan 1980 to July 1981 is included in the period 79-89. The sum along columns (across four components, and across fourteen sectors) equals the total listed in the first row. 


\begin{tabular}{rr|rrrr|r|rrrr|r|rrrr}
\hline \hline Sec & Sum & $\omega$ & $\lambda$ & $\varepsilon$ & $p$ & Sum & $\omega$ & $\lambda$ & $\varepsilon$ & $p$ & Sum & $\omega$ & $\lambda$ & $\varepsilon$ & $p$ \\
\hline Sum & 100.0 & 26.5 & -2.7 & 74.7 & 1.5 & 100.0 & -0.6 & -1.1 & 97.6 & 4.1 & 100.0 & 42.6 & -4.4 & 61.4 & 0.4 \\
\hline AGR & 11.0 & 0.2 & 1.0 & 1.5 & 8.4 & 14.7 & -0.7 & 0.6 & 2.6 & 12.2 & 6.1 & 0.6 & 0.4 & 1.2 & 3.9 \\
MIN & 0.0 & 0.0 & 0.1 & 1.6 & -1.7 & -0.1 & -0.9 & 0.3 & 3.9 & -3.4 & 0.4 & 0.9 & -0.4 & 0.7 & -0.8 \\
UTI & 2.5 & 0.3 & -0.5 & 0.8 & 1.9 & 3.6 & -0.1 & -0.5 & 1.0 & 3.1 & 2.5 & 0.5 & -0.5 & 1.1 & 1.4 \\
CON & 2.2 & 2.8 & 0.0 & 1.3 & -1.9 & 0.7 & 2.1 & -0.5 & 2.4 & -3.3 & 3.5 & 2.1 & 0.5 & 2.5 & -1.5 \\
MAN & 40.0 & 5.1 & -1.1 & 34.3 & 1.8 & 49.7 & -2.2 & 0.1 & 45.6 & 6.3 & 29.2 & 4.7 & -1.8 & 28.2 & -2.0 \\
WTR & 6.5 & 1.4 & 0.1 & 3.8 & 1.3 & 8.1 & 0.5 & 0.1 & 7.9 & -0.5 & 4.1 & 1.6 & 0.0 & -0.7 & 3.3 \\
RTR & 6.9 & -0.3 & 0.0 & 10.9 & -3.6 & 8.7 & 0.9 & -0.1 & 12.6 & -4.7 & 4.5 & -2.5 & -0.1 & 9.1 & -2.0 \\
TRW & 4.3 & 1.8 & 0.0 & 4.4 & -1.9 & 3.9 & 0.1 & 0.0 & 5.9 & -2.1 & 4.8 & 1.5 & 0.0 & 4.9 & -1.7 \\
INF & 5.7 & -0.4 & -1.0 & 7.2 & 0.0 & 4.2 & -1.0 & -0.1 & 5.6 & -0.2 & 7.3 & -0.5 & -1.8 & 8.1 & 1.5 \\
FIN & 13.7 & 10.0 & -0.1 & 3.5 & 0.3 & -0.1 & -1.3 & -0.1 & -0.1 & 1.4 & 28.8 & 23.1 & -0.1 & 4.3 & 1.4 \\
PBS & 5.4 & 3.9 & 0.0 & 1.8 & -0.3 & 4.7 & -0.7 & 0.1 & 5.0 & 0.3 & 7.2 & 10.1 & 0.2 & -1.2 & -1.9 \\
EHS & 0.2 & -0.1 & -0.8 & 0.8 & 0.3 & 0.5 & 0.5 & -0.5 & 0.8 & -0.3 & -0.3 & -0.9 & -0.7 & 1.2 & 0.2 \\
AER & 1.4 & 0.3 & 0.0 & 3.2 & -2.1 & 1.3 & -0.5 & 0.0 & 4.8 & -3.0 & 1.6 & 1.2 & 0.0 & 1.6 & -1.1 \\
OTH & 0.1 & 1.4 & -0.2 & -0.2 & -0.8 & 0.2 & 2.6 & -0.4 & -0.4 & -1.6 & 0.2 & 0.1 & -0.1 & 0.3 & -0.1 \\
\hline
\end{tabular}

Table 2: Variance decomposition of annual changes in the US labor share: The table presents a variance decomposition of the annual changes in the labor share and its four Divisia decomposition components by sectors. The four components are real compensation, employment structure, labor productivity and relative prices, from left to right. The first block of columns represents the entire sample (1949-2017), the second block the "Golden Age" (1949-1979) and the third the "Neoliberal Era" (1979-2017). Each sectoral components represents the percentage point contribution to sectoral and component contributions, so that row and column totals sum to $100 \%$ of the aggregate labor share change.

\begin{tabular}{rr|rrrr|r|rrrr|r|rrrr}
\hline \hline Sec & Sum & $\omega$ & $\lambda$ & $\varepsilon$ & $p$ & Sum & $\omega$ & $\lambda$ & $\varepsilon$ & $p$ & Sum & $\omega$ & $\lambda$ & $\varepsilon$ & $p$ \\
\hline Sum & 100 & 5752 & 654 & -6449 & 143 & 100 & 793 & 62 & -709 & -46 & 100 & 775 & 121 & -1049 & 54 \\
AGR & 212 & 145 & 207 & -557 & 418 & 35 & 25 & 48 & -75 & 36 & 16 & 9 & 10 & -48 & 45 \\
MIN & -28 & 197 & 85 & -156 & -154 & -7 & 22 & 11 & 5 & -44 & -2 & 26 & 14 & -46 & 5 \\
UTI & -54 & 96 & 26 & -93 & -83 & -11 & 15 & 2 & -17 & -11 & -5 & 12 & 9 & -11 & -15 \\
CON & 58 & 412 & 3 & -26 & -331 & 11 & 57 & 2 & -23 & -25 & 1 & 51 & -1 & 24 & -73 \\
MAN & -412 & 1533 & 90 & -2805 & 770 & 22 & 316 & -6 & -329 & 41 & -111 & 156 & 28 & -472 & 177 \\
WTR & -81 & 384 & 2 & -848 & 381 & 3 & 52 & 0 & -88 & 38 & -25 & 50 & 2 & -142 & 66 \\
RTR & 58 & 253 & 6 & -401 & 200 & 25 & 36 & 3 & -21 & 7 & -9 & 30 & -1 & -82 & 44 \\
TRW & -8 & 319 & -14 & -328 & 15 & 3 & 65 & -4 & -62 & 3 & -5 & 12 & 0 & -18 & 1 \\
INF & -234 & 297 & 19 & -684 & 134 & -11 & 45 & 0 & -62 & 6 & -52 & 35 & 8 & -132 & 38 \\
FIN & -124 & 463 & -21 & -396 & -170 & -10 & 33 & -3 & -15 & -25 & -30 & 101 & 0 & -122 & -8 \\
PBS & 315 & 713 & 121 & -260 & -259 & 14 & 43 & 3 & -24 & -9 & 58 & 145 & 22 & -36 & -74 \\
EHS & 282 & 457 & 124 & 176 & -474 & 27 & 42 & 8 & 12 & -36 & 43 & 77 & 29 & 40 & -102 \\
AER & 61 & 191 & 28 & 45 & -202 & 2 & 16 & 1 & 5 & -20 & 9 & 30 & 4 & 6 & -30 \\
OTH & 53 & 294 & -21 & -116 & -103 & -1 & 25 & -2 & -17 & -7 & 11 & 42 & -2 & -11 & -19 \\
\hline
\end{tabular}

Table 3: Growth contributions to annual changes in the US labor share: The table presents growth contributions in percentage points by the four sectoral Divisia decomposition components to the annual changes in the labor share. The four components are real compensation, employment structure, labor productivity and relative prices, from left to right. The first block of columns represents the entire sample (1949-2017), the second block the "Golden Age" (1949-1979) and the third the "Neoliberal Era" (1979-2017). Each sectoral components represents the percentage point contribution to sectoral and component contributions, so that row and column totals sum to $100 \%$ of the aggregate labor share change. Figure 4 presents selected growth contributions visually. 


\begin{tabular}{r|rrrr|rrrr}
\hline \hline Sec & $\Delta \psi$ & $\Delta E S$ & $\Delta O S$ & $\hat{\varepsilon}$ & $\Delta \psi$ & $\Delta E S$ & $\Delta O S$ & $\hat{\varepsilon}$ \\
\hline AGR & 8. & -3.8 & -7.5 & 3.2 & 15.3 & -1. & -2.4 & 4.4 \\
MIN & -1.8 & -1.1 & -0.7 & 0 & 2.4 & -0.7 & -0.8 & 3. \\
UTI & -7.7 & -0.2 & 0.8 & 2.3 & -4.9 & -0.4 & -0.7 & 1. \\
CON & 0.3 & 0.7 & 1.3 & 1.1 & -4.3 & -0.4 & -0.5 & -0.7 \\
MAN & 2.4 & -8.7 & -2.5 & 3. & -23. & -15.8 & -13.5 & 3.6 \\
WTR & 1.6 & 0.4 & 0.5 & 3.3 & -13.4 & -1.3 & -0.5 & 3.4 \\
RTR & 12.6 & 2.8 & -2.2 & 0.6 & -7.5 & -1.2 & -2.1 & 1.7 \\
TRW & 1.1 & -3.1 & -2. & 2.8 & -6. & 0.2 & -1. & 0.7 \\
INF & -14.2 & -0.3 & 1.8 & 3.9 & -24.8 & -0.7 & 1.4 & 3.9 \\
FIN & -3. & 2.1 & 3.3 & 1. & -4.9 & 0 & 4.2 & 2.7 \\
PBS & 8.1 & 4.4 & 3.8 & 1.1 & 6.1 & 8. & 9.1 & 0.5 \\
EHS & 20.7 & 6. & 3.8 & -0.8 & -1.9 & 9.2 & 5.6 & -0.8 \\
AER & -0.6 & 2.1 & 0.3 & -0.3 & 3. & 4.8 & 1.4 & -0.2 \\
OTH & -8.6 & -1.4 & -0.6 & 1.3 & 7.8 & -0.8 & -0.1 & 0.7 \\
\hline
\end{tabular}

Table 4: Sectoral productivity growth and structural change: The table reports data on structural and distributive change as well as labor productivity growth by sectors for Golden Age (first four columns) and Neoliberal Era (last four columns). Difference between end-of-period and beginning-of-period labor share $(\Delta \psi)$, employment share $(\Delta E S)$ and value added share $(\Delta O S)$ are shown in percentage points, as is the average annual growth rate of labor productivity $(\hat{\varepsilon})$. Data on employment share changes and productivity growth are shown as well in the top two panels of Figure 6. 